\title{
The CU Airborne MAX-DOAS instrument: vertical profiling of aerosol extinction and trace gases
}

\author{
S. Baidar ${ }^{1,2}$, H. Oetjen ${ }^{1,}{ }^{*}$, S. Coburn ${ }^{1}$, B. Dix ${ }^{1}$, I. Ortega ${ }^{1}$, R. Sinreich ${ }^{1}$, and R. Volkamer ${ }^{1,2}$ \\ ${ }^{1}$ Department of Chemistry and Biochemistry, University of Colorado, Boulder, CO 80309, USA \\ ${ }^{2}$ Cooperative Institute for Research in Environmental Sciences (CIRES), Boulder, CO 80309, USA \\ * now at: UCLA/JPL Joint Institute for Regional Earth System Science and Engineering (JIFRESSE), \\ Los Angeles, CA 90095, USA
}

Correspondence to: R. Volkamer (rainer.volkamer@colorado.edu)

Received: 2 August 2012 - Published in Atmos. Meas. Tech. Discuss.: 26 September 2012

Revised: 16 February 2013 - Accepted: 1 March 2013 - Published: 14 March 2013

\begin{abstract}
The University of Colorado Airborne Multi-Axis Differential Optical Absorption Spectroscopy (CU AMAXDOAS) instrument uses solar stray light to detect and quantify multiple trace gases, including nitrogen dioxide $\left(\mathrm{NO}_{2}\right)$, glyoxal (CHOCHO), formaldehyde (HCHO), water vapor $\left(\mathrm{H}_{2} \mathrm{O}\right)$, nitrous acid (HONO), iodine monoxide (IO), bromine monoxide $(\mathrm{BrO})$, and oxygen dimers $\left(\mathrm{O}_{4}\right)$ at multiple wavelengths (absorption bands at 360, 477, 577, $632 \mathrm{~nm}$ ) simultaneously in the open atmosphere. The instrument is unique as it (1) features a motion compensation system that decouples the telescope field of view from aircraft movements in real time $\left(<0.35^{\circ}\right.$ accuracy), and (2) includes measurements of solar stray light photons from nadir, zenith, and multiple elevation angles forward and below the plane by the same spectrometer/detector system. Sets of solar stray light spectra collected from nadir to zenith scans provide some vertical profile information within $2 \mathrm{~km}$ above and below the aircraft altitude, and the vertical column density (VCD) below the aircraft is measured in nadir view. Maximum information about vertical profiles is derived simultaneously for trace gas concentrations and aerosol extinction coefficients over similar spatial scales and with a vertical resolution of typically $250 \mathrm{~m}$ during aircraft ascent/descent.

The instrument is described, and data from flights over California during the CalNex (California Research at the Nexus of Air Quality and Climate Change) and CARES (Carbonaceous Aerosols and Radiative Effects Study) air quality field campaigns is presented. Horizontal distributions of $\mathrm{NO}_{2}$ VCD (below the aircraft) maps are sampled with typically $1 \mathrm{~km}$ resolution, and show good
\end{abstract}

agreement with two ground-based MAX-DOAS instruments (slope $=0.95 \pm 0.09, R^{2}=0.86$ ). As a case study vertical profiles of $\mathrm{NO}_{2}, \mathrm{CHOCHO}, \mathrm{HCHO}$, and $\mathrm{H}_{2} \mathrm{O}$ concentrations and aerosol extinction coefficients, $\varepsilon$, at $477 \mathrm{~nm}$ calculated from $\mathrm{O}_{4}$ measurements from a low approach at Brackett airfield inside the South Coast Air Basin (SCAB) are presented. These profiles contain $\sim 12$ degrees of freedom (DOF) over a $3.5 \mathrm{~km}$ altitude range, an independent information approximately every $250 \mathrm{~m}$. The boundary layer $\mathrm{NO}_{2}$ concentration, and the integral aerosol extinction over height (aerosol optical depth, AOD) agrees well with nearby ground-based in situ $\mathrm{NO}_{2}$ measurement, and AERONET station. The detection limits of $\mathrm{NO}_{2}, \mathrm{CHOCHO}, \mathrm{HCHO}, \mathrm{H}_{2} \mathrm{O}_{442}, \varepsilon_{360}, \varepsilon_{477}$ for $30 \mathrm{~s}$ integration time spectra recorded forward of the plane are $5 \mathrm{ppt}, 3 \mathrm{ppt}, 100 \mathrm{ppt}, 42 \mathrm{ppm}, 0.004 \mathrm{~km}^{-1}, 0.002 \mathrm{~km}^{-1}$ in the free troposphere (FT), and $30 \mathrm{ppt}, 16 \mathrm{ppt}, 540 \mathrm{ppt}$, $252 \mathrm{ppm}, 0.012 \mathrm{~km}^{-1}, 0.006 \mathrm{~km}^{-1}$ inside the boundary layer (BL), respectively. Mobile column observations of trace gases and aerosols are complimentary to in situ observations, and help bridge the spatial scales that are probed by satellites and ground-based observations, and predicted by atmospheric models.

\section{Introduction}

Airborne Differential Optical Absorption Spectroscopy (DOAS) measurements of different trace gases in the atmosphere by solar stray light started in late 1980s and has come a long way since then. Early studies were focused on 


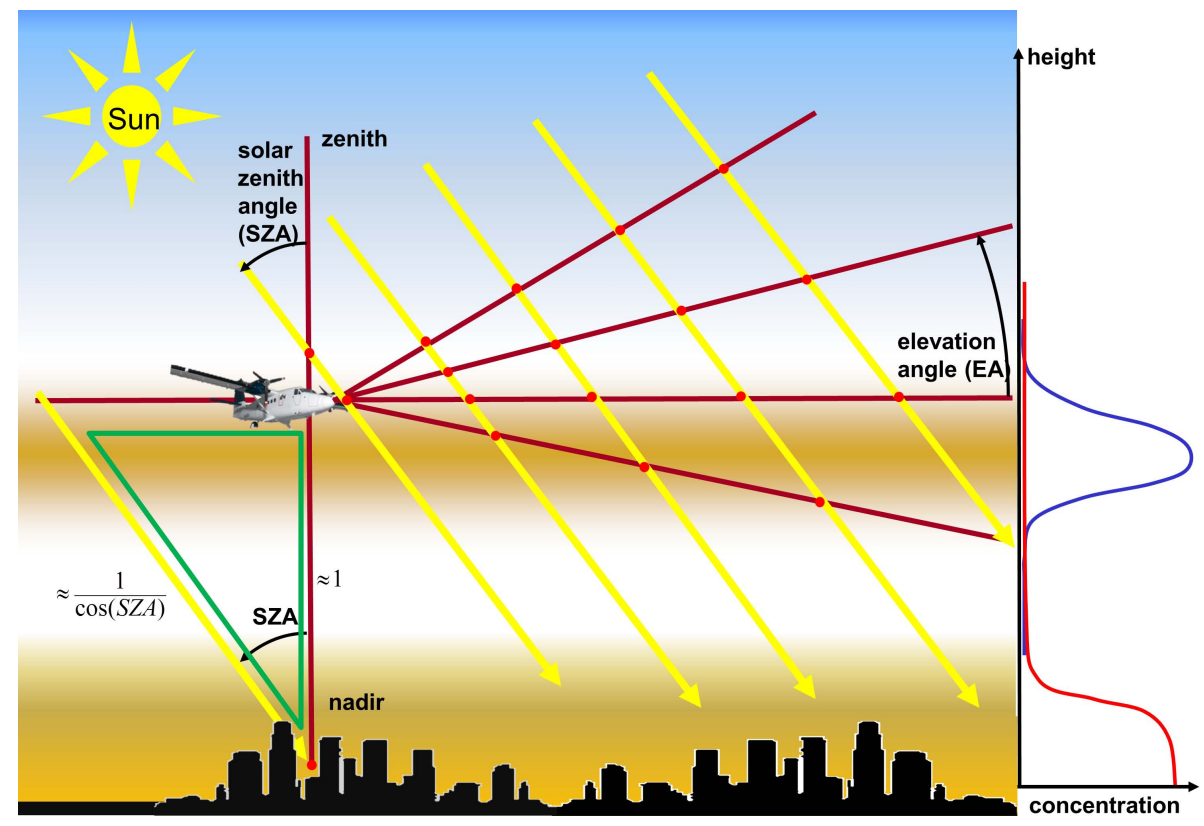

Fig. 1. Schematic of the AMAX-DOAS measurement principle. Individual EAs contain different amounts of information from different layers in the atmosphere. The inset (green triangle) illustrates the geometric approximation used to convert nadir dSCDs to VCDs.

obtaining column integrals of stratospheric trace gases like nitrogen dioxide $\left(\mathrm{NO}_{2}\right)$ (Wahner et al., 1990a), chlorine dioxide (OClO) (Schiller et al., 1990), and bromine oxide (BrO) (Wahner et al., 1990b) from zenith measurements. First retrievals of trace gas concentrations close to the aircraft altitude were reported by Petritoli et al. (2002) for stratospheric ozone $\left(\mathrm{O}_{3}\right)$. These studies were followed by the application of the AMAX-DOAS technique to obtain tropospheric columns for $\mathrm{NO}_{2}$ (Melamed et al., 2003; Heue et al., 2005; Wang et al., 2005) and sulfur dioxide $\left(\mathrm{SO}_{2}\right)$ (Wang et al., 2006; Melamed et al., 2008) over polluted regions. These instruments used multiple telescopes, most notably zenith and nadir, to collect scattered sunlight. Over the past few years, building on the well-established limb observation technique (e.g., McElroy, 1988; Weidner et al., 2005 and references within), the focus has shifted towards retrievals of vertical distribution of trace gases from the aircraft using several limb viewing telescopes. Figure 1 shows the conceptual viewing geometry of the so-called Airborne Multi-Axis DOAS (AMAX-DOAS) technique. Individual elevation angles (EAs) contain different amounts of information from different layers in the atmosphere and hence can be used to infer vertical distributions of trace gases. Bruns et al. (2006) first reported profiles of $\mathrm{NO}_{2}$ over the Po valley from an airborne MAX-DOAS instrument with four telescopes pointing at fixed EAs. A boundary layer $\mathrm{NO}_{2}$ profile was obtained by Dix et al. (2009) using multiple lines of sight (LOS) and a descent of an aircraft. Prados-Roman et al. (2011) used the LOS parallel to the plane and the aircraft descent to retrieve vertical profiles of $\mathrm{BrO}$ in the Arctic. Most recently, a limb scanning airborne DOAS instrument was developed at the Belgium Institute for Space Aeronomy (BIRA) to obtain vertical distribution of trace gases like $\mathrm{NO}_{2}$ (Merlaud et al., 2011). Most airborne DOAS instruments use either a single or multiple fixed LOS and a spectrum collected from the same EA is used as the reference spectrum for DOAS analysis. However, these instruments lack active control of the viewing geometry of the telescope during the flight. Pitch and roll information from the aircraft is used during postprocessing to calculate the true viewing angle at the time of measurement during the flight. This often leads to a range of EAs assigned to measurements, and results in a loss of sensitivity to a given layer in the atmosphere compared to when the EAs are actively controlled in order to retrieve vertical profile information of trace gases. Active control of EAs along with careful selection of EAs also allows for maximization of the degrees of freedom (DOF).

Here we describe the CU AMAX-DOAS instrument, a new and improved AMAX-DOAS instrument with capabilities to motion stabilize and collect spectra from multiple axes using a single telescope. The CU AMAX-DOAS instrument has the capability to access zenith, nadir and limb viewing geometry by means of a single, rotatable prism telescope that is coupled to a motion compensation system. The motion compensation system includes angle sensors to measure pitch and roll angles of the aircraft, and a feedback loop to correct the telescope position for pitch and roll angles in real time. This ensures a constant desired EA is maintained during spectra acquisition in flight. Isolation of the telescope from the aircraft movements enables us to systematically 
probe the atmosphere with desired sets of EAs in order to retrieve vertical profiles of trace gases and aerosol extinction simultaneously, and with the highest possible information content. The use of a single telescope to collect spectra from zenith and other EAs (nadir, and forward of the plane) further enables the zenith spectra to be used as the Fraunhofer reference spectrum in the DOAS analysis. Zenith spectra usually contain the least amount of tropospheric absorbers, and the ability to record zenith spectra close in time to other EA spectra assures that absorbers above the plane are characterized with minimum difference in radiation fields, and makes the instrument inherently more sensitive to absorbers near and below the aircraft altitude (Volkamer et al., 2009a).

The CU AMAX-DOAS instrument was successfully deployed from 19 May-19 July 2010 as part of two air quality studies in California, namely the California Research at the Nexus of Air Quality and Climate Change (CalNex) (see the overview paper by Ryerson et al., 2013) and the Carbonaceous Aerosols and Radiative Effects Study (CARES) (see the overview paper by Zaveri et al., 2012). A total of 52 research flights were performed during this deployment and here we focus on results from one flight on 16 July 2010 to describe the technique and characterize instrument performance. In Sect. 2 the CU AMAX-DOAS instrument is described and the instrument configuration is introduced. Section 3 describes the DOAS analysis procedures, radiative transfer model (RTM) calculations, and algorithms to retrieve VCDs (vertical column densities) and vertical profiles of the trace gas concentrations and aerosol extinction. Section 4 demonstrates the capability of the new instrument. As a case study, vertical profiles of nitrogen dioxide $\left(\mathrm{NO}_{2}\right)$, glyoxal (CHOCHO), formaldehyde ( $\left.\mathrm{HCHO}\right)$, water vapor $\left(\mathrm{H}_{2} \mathrm{O}\right)$ and aerosol extinction at $477 \mathrm{~nm}$ are retrieved from a low approach at Brackett airfield in the South Coast Air Basin (SCAB). Finally, as a validation, CU AMAXDOAS $\mathrm{NO}_{2}$ VCDs are compared with VCDs measured by two ground-based MAX-DOAS instruments that were regularly overpassed during flights, the boundary layer $\mathrm{NO}_{2}$ concentration of the retrieved vertical profile is compared to a ground-based in situ sensor concentration, and the integral aerosol extinction over height, i.e., aerosol optical depth (AOD) is compared with data from an AERONET station.

Appendix A shows the glossary of frequently used abbreviations in the paper.

\section{The CU AMAX-DOAS instrument}

The CU-AMAX-DOAS instrument collects spectra of scattered sunlight between 330 and $720 \mathrm{~nm}$ at different EAs. The scattered sunlight spectra are analyzed for the presence of absorbers like $\mathrm{NO}_{2}, \mathrm{CHOCHO}, \mathrm{HCHO}, \mathrm{H}_{2} \mathrm{O}, \mathrm{HONO}$, IO, $\mathrm{BrO}, \mathrm{O}_{4}$ using the DOAS method (Platt and Stutz, 2008). $\mathrm{NO}_{2}, \mathrm{CHOCHO}, \mathrm{HCHO}, \mathrm{H}_{2} \mathrm{O}$ and $\mathrm{O}_{4}$ data will exemplarily be presented in this paper. The instrument consists of
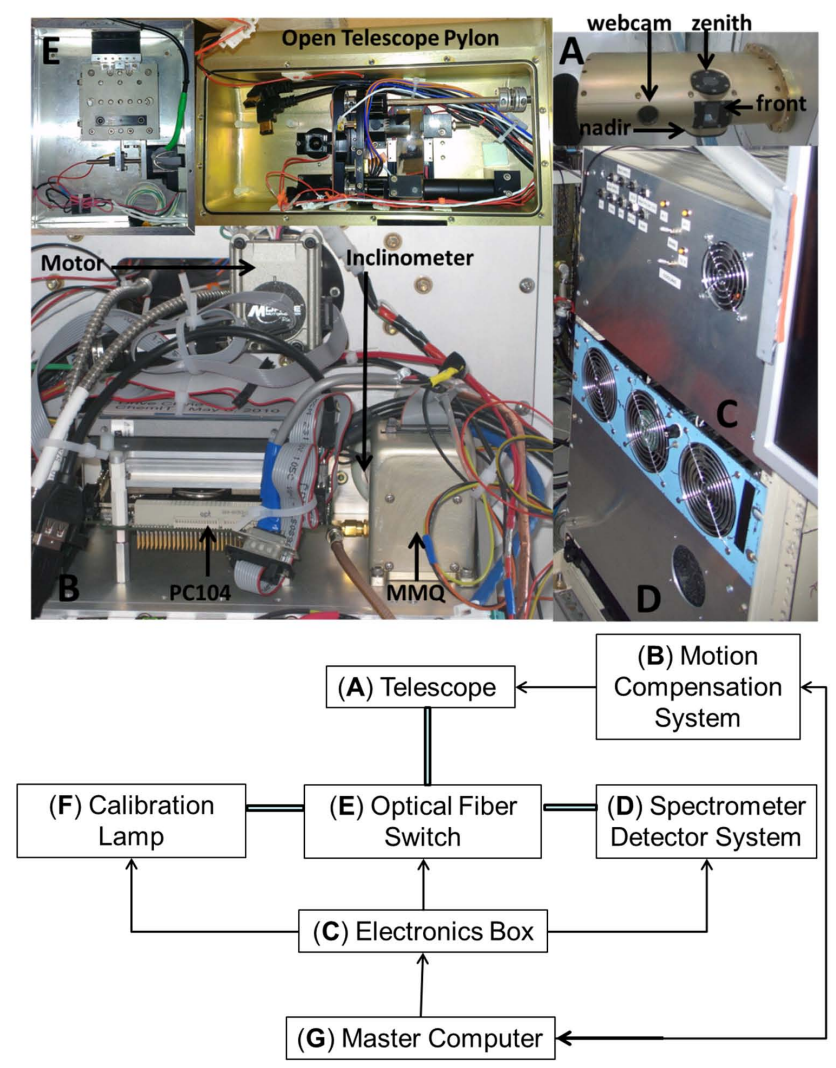

Fig. 2. CU AMAX-DOAS instrument setup aboard the NOAA Twin Otter during the CalNex and CARES campaigns.

a telescope pylon mounted outside of a window plate on a National Oceanic and Atmospheric Administration (NOAA) Twin Otter remote sensing research aircraft. The collected photons are transferred via optical fibers to two synchronized spectrometer/detector systems that are housed inside the aircraft fuselage. An optical fiber switch box is placed in between the light sources (telescopes and Hg calibration lamp) and the spectrometer/detector systems to select between different light sources at a given time. The $\mathrm{Hg}$ calibration lamp is used to characterize the optical resolution of the spectrometer/detector system. The instrumental setup is shown in Fig. 2.

\subsection{Telescope system}

The telescope is designed for high light throughput and a very narrow vertical field of view $\left(\mathrm{FOV}, 0.3^{\circ} \times 5.89^{\circ}\right)$. It comprises a $1 / 2^{\prime \prime}$ rotating prism, a $1 / 2^{\prime \prime}$ lens tube with a $1 / 2^{\prime \prime}$ $\mathrm{f} / 4$ lens and a stepper motor. All the telescope components are housed in a telescope pylon - an aluminum housing with quartz windows, which is mounted outside of a window plate on a NOAA Twin Otter research aircraft. The rotating prism is installed with $0^{\circ}$ EA parallel to the aircraft heading and is driven by a stepper motor with an internal encoder to rotate vertically. The prism is capable of making a complete $360^{\circ}$ 
rotation and hence allows characterization of the air masses above, below and in front of the aircraft using the same telescope. Viewing directions behind the aircraft are not accessible due to the structural design of the pylon including the placement of viewing ports. An additional telescope with a fixed EA is therefore present in the pylon to reach some of the inaccessible viewing geometries of the rotating prism. This telescope was rarely used during the CalNex and CARES campaigns, and data from this telescope are not presented in this paper. The viewing ports on the pylon are heated to prevent formation of ice at higher altitudes. The pylon also includes two webcams: a downward and a forward looking one, to capture atmospheric conditions during the flight and to filter for clouds during post-processing of data. The light collected by the rotatable prism is focused via a lens tube onto a 12-m-long fiber bundle consisting of $72 \times 145 \mu \mathrm{m}$ fibers. The fiber bundle is configured into two rows of 36 fibers at the telescope end and a circular arrangement at the other. The end of the fiber bundle away from the telescope is connected to a custom-made optical fiber switch box.

\subsection{Optical fiber switch box}

The optical fiber switch box is used to select between different incoming light sources. It consists of a translational stage mounted to a stepper motor linear actuator. The fibers from the telescopes and $\mathrm{Hg}$ calibration lamp are connected to one end of the box. $\mathrm{Hg}$ spectra were taken before, after and at regular intervals during flights to check the stability of the spectrograph's optical resolution. A 10-m-long 1.7-mmdiameter silica monofiber, which is used as a mixing fiber to minimize polarization effects, is mounted on the translational stage opposite the incoming fibers from the light sources. The motor of the linear actuator drives the platform to place the monofiber directly in front of the desired fiber with the incoming light at a given time. The other end of the monofiber is connected to a bifurcated fiber bundle $(72 \times 145 \mu \mathrm{m})$ to deliver light to two spectrometers simultaneously. The bifurcated ends are aligned in a single row of 36 fibers to connect to the spectrograph entrance slit.

\subsection{Spectrometer and detector system}

Two spectrometers and their respective detectors are housed in a standard $19^{\prime \prime}$ aluminum instrument rack $\left(19^{\prime \prime} \times 22^{\prime \prime} \times 101 / 2^{\prime \prime}\right)$ with modifications to the bottom and top plates for added stability. The spectrometers are Princeton Instrument Acton SP2150 Imaging Czerny-Turner spectrometers with PIXIS 400 back illuminated charge-coupled devices (CCDs) detectors. The first spectrometer (later referred to as the $\mathrm{O}_{4}$ spectrometer) is equipped with a 500 grooves $/ \mathrm{mm}$ grating, blazed at $330 \mathrm{~nm}$. It covers 350 $720 \mathrm{~nm}$ and is used to measure all four major $\mathrm{O}_{4}$ absorption bands at 360, 477, 577 and $630 \mathrm{~nm}$. The second spectrometer (later referred to as trace gas - TG - spectrometer) covers a wavelength range from $330-470 \mathrm{~nm}$ with a custom 1000 grooves $/ \mathrm{mm}$ ( $250 \mathrm{~nm}$ blaze wavelength) grating. It is used to measure all other trace gases. The optical resolutions of the $\mathrm{O}_{4}$ and TG spectrometers were $\sim 2.2 \mathrm{~nm}$ $(\sim 7.7$ pixels $)$ and $\sim 0.7 \mathrm{~nm}(\sim 6.7$ pixels $)$, respectively, inferred from the full width at half maximum (FWHM) of a representative $\mathrm{Hg}$ line. The CCDs are cooled to $-30^{\circ} \mathrm{C}$ to reduce dark current. The temperatures of the spectrometers are actively controlled with heaters, while the instrument rack box temperature is actively cooled using peltier cooling units assuring a constant temperature over a range of varying ambient temperatures. Please refer to Coburn et al. (2011) for additional information on temperature stability, data acquisition and electronic and dark current correction for a comparable instrument. To suppress spectrometer stray light from longer wavelength (above $470 \mathrm{~nm}$ ) and to gain maximum intensities in our regions of interest, i.e., between $330-470 \mathrm{~nm}$, in the TG spectrometer, two filters - a BG3 and a BG38 were placed immediately after the shutter.

\subsection{Motion compensation system}

The motion compensation system is used to correct the viewing geometry of the telescope for the aircraft pitch and roll effects during the flight. It consists of a PC104 computer connected to the prism motor and two angle sensors, a Systron Donner Inertial MMQ-G, and an electronic inclinometer. The MMQ-G is a small robust global positioning system (GPS) -based inertial navigation system (INS). It provides accurate 3-D position, time, velocity, and attitude. It is primarily used to measure the pitch and roll angles of the aircraft for our application, and has an angle accuracy of $5 \mathrm{mrad}\left(\sim 0.29^{\circ}\right)$. The information from the sensor is processed by custom LabVIEW software into the coordinate system along the horizon. It is then used to drive the stepper motor of the prism to a new position such that it corrects for the aircraft's movement and keeps the telescope at the desired EA. The software has capability for a $100 \mathrm{~Hz}$ loop rate, and was typically operated at $10 \mathrm{~Hz}$. The stepper motor has a precision of $0.01^{\circ}$ but is limited by the resolution of the internal encoder $\left(0.2^{\circ}\right)$ to precisely read back the position of the motor. The MMQ-G, inclinometer and the telescope prism are mounted on planes parallel to the ground such that the EA of the telescope and the pitch of the aircraft read zero simultaneously. The inclinometer is used as a backup during flights for situations when the GPS signal required for the MMQ-G is lost. The theoretical angle accuracy of the motion compensation system is $0.35^{\circ}$, considering the MMQ-G accuracy of $\sim 0.29^{\circ}(1 \sigma)$ and motor internal encoder resolution of $0.2^{\circ}$. The system is configured to reset the motor when it does not reach a given position within a desired tolerance level by a fixed time interval. The same motion compensation system has also been integrated as part of another telescope pylon designed for adaptation of the CU AMAX-DOAS instrument aboard the NSF/NCAR GV HIAPER aircraft. 

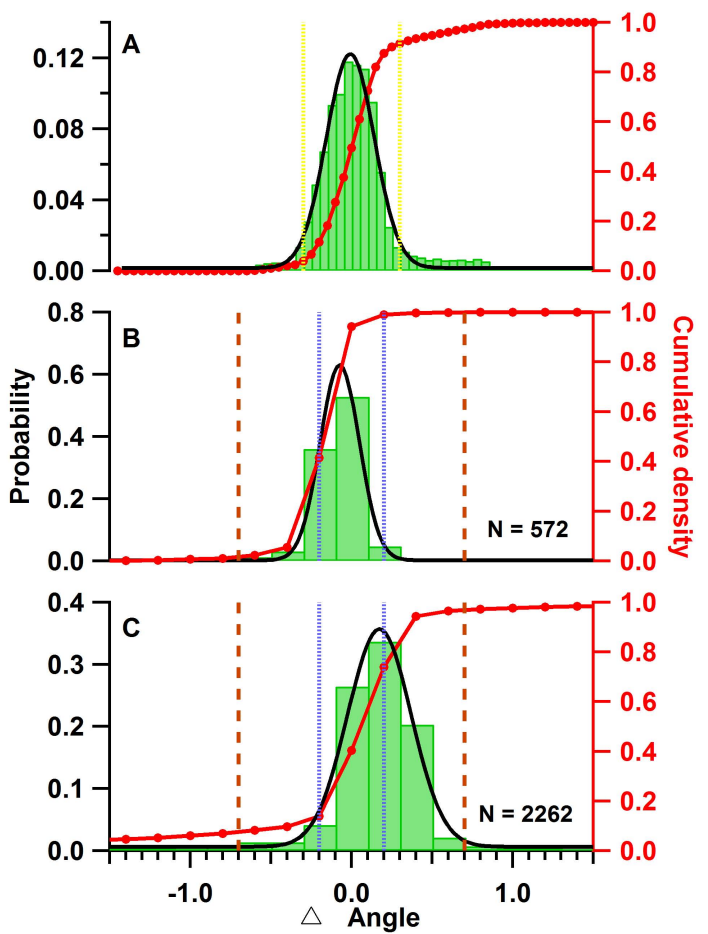

Fig. 3. (A) Distribution of difference in pitch angle of the aircraft measured at real time by the MMQ-G angle sensor of the CUAMAX-DOAS and aircraft avionics system of NSF/NCAR GV HIAPER aircraft during a research flight on 24 February 2012. $1 \sigma$ angle accuracy $\left(0.29^{\circ}\right)$ of the MMQ-G sensor is shown in yellow dotted lines. $1 \sigma$ for the Gaussian fit (black line) is $0.15^{\circ}$. Distribution of elevation angle accuracy of the CU AMAX-DOAS telescope (B) from the above-mentioned flight on NSF/NCAR GV HIAPER flight and (C) during RF\#46 aboard NOAA Twin Otter on 16 July 2010. $1 \sigma$ for the Gaussian fits (black lines) are $0.12^{\circ}$ and $0.2^{\circ}$ for instrument aboard HIAPER and Twin Otter aircraft, respectively, and are within the resolution of the motor internal encoder $\left(0.2^{\circ}\right)$, shown in blue dotted lines. Brown dashed lines represent the motor tolerance level $\left(0.7^{\circ}\right)$ set in the software before an automatic reset of the motor position takes place. The red lines represent the cumulative densities.

\subsection{Performance of the motion compensation system}

Figure 3 shows the performance of the system during research flights aboard the GV HIAPER and Twin Otter aircrafts. GV HIAPER flights provide an excellent opportunity to test the system as the aircraft pitch and roll angles measured by the aircraft avionics system during the flight are recorded, while avionics data for the Twin Otter flights are not available. The histogram of differences in aircraft pitch angle recorded at $1 \mathrm{~Hz}$ frequency measured by NSF/NCAR GV HIAPER aircraft avionics and our MMQ-G recording during a research flight $(\sim 8 \mathrm{~h})$ on 24 February 2012 is plotted as a probability density function in Fig. 3a. A Gaussian fit (black line) to the histogram has a $1 \sigma$ deviation of $0.15^{\circ}$, which is less than the $1 \sigma$ accuracy $\left(0.29^{\circ}\right.$, yellow line in Fig. 3a) of the MMQ-G pitch measurement. This shows that the MMQ-G measures the aircraft pitch and roll angles with sufficient accuracy, which are then being used for real-time pointing corrections. Figure $3 b$ shows the difference in desired EA and the real-time EA read back from the motor internal encoder as a probability density for the same flight. The $1 \sigma$ of the Gaussian fit to the histogram $\left(0.12^{\circ}\right)$ is smaller than the resolution of the motor internal encoder confirming that the telescope position was corrected for the aircraft movements within our ability to read back the motor position. The width of the histograms (Fig. 3b and c) is chosen based on the resolution of the motor internal encoder, i.e., $0.2^{\circ}$.

A similar plot from a research flight $(\sim 4 \mathrm{~h})$ on 16 July 2010 aboard the NOAA Twin Otter is shown in Fig. $3 \mathrm{c}$ and the $1 \sigma$ of the Gaussian fit is $0.2^{\circ}$. This slightly larger distribution is within the resolution of the motor internal encoder. The fact that the $1 \sigma$ for both platforms is less than or equal to the ability with which we can accurately read the position of the motor demonstrates that this motion compensation is suitable for a wide range of moving platforms. Since the precision of the stepper motor is $0.01^{\circ}$, an order of magnitude better than resolution of the motor internal encoder, it is very likely that the difference between the real-time and desired EA is smaller than what is being read back from the internal encoder, and the overall angle accuracy $(1 \sigma)$ of the motion compensation system is better than $0.35^{\circ}$. The offset of $0.17^{\circ}$ for the Gaussian fit in Fig. $3 \mathrm{c}$ is probably due to some remaining misalignment between the angle sensor and the motor, but is smaller than the accuracy of the angle sensor.

The tolerance level (brown dashed lines in Fig. 3b and c) above which the motor performs an automatic reset was set to $0.7^{\circ}$ ( $2 \sigma$ theoretical accuracy) for the campaigns described here. The statistical distribution of the EA difference indicates that the desired position of the motor was achieved after the reset.

\subsection{Field deployment and operation during CalNex and CARES}

The CU AMAX-DOAS instrument was deployed aboard the NOAA Twin Otter remote sensing research aircraft during the CalNex and CARES field campaigns from 19 May19 July 2010 in California after test flights in 2008 and 2009. The pylon was modified significantly after 2009 . The aircraft is an unpressurized twin-engine turboprop with an altitude ceiling of $\sim 4 \mathrm{~km}$ a.s.l. (above sea level) without supplemental cabin oxygen. It has a normal cruising speed of $\sim 65 \mathrm{~m} \mathrm{~s}^{-1}$ and ascent rate of $\sim 10 \mathrm{~m} \mathrm{~s}^{-1}$, making it particularly suitable for surveying vertical and horizontal distributions of trace gases in a polluted urban environment. During CalNex, the NOAA Twin Otter aircraft was stationed at Ontario, CA, and joined the CARES campaign from 1629 June 2010 at Sacramento, CA. The plane was equipped 
with a suite of remote sensing instruments: the University of Colorado deployed the (1) CU AMAX-DOAS instrument and (2) two 4-channel radiometers (zenith and nadir viewing) to measure surface albedo (SA); further, NOAA/ESRL/CSD deployed (3) a nadir-pointing TOPAZ (Tunable Ozone Profiler for Aerosol and oZone) lidar (Alvarez II et al., 2011), which measures vertical distribution of ozone $\left(\mathrm{O}_{3}\right)$, and the (4) University of Leeds HALO Doppler lidar (Pearson et al., 2009), which measures 3-D wind fields, as well as (5) a nadir pointing infrared pyrometer and (6) an in situ $\mathrm{O}_{3}$ monitor.

The purposes of the CU AMAX-DOAS deployment were the following: to measure horizontal and vertical distributions of $\mathrm{NO}_{2}, \mathrm{HCHO}, \mathrm{CHOHO}$ and aerosol extinction over California - particularly over the SCAB - to characterize boundary conditions for comparison with atmospheric models, and to probe for pollutant concentrations above the boundary layer (BL). $\mathrm{NO}_{2}, \mathrm{HCHO}$ and $\mathrm{CHOCHO}$ play important roles in atmospheric chemistry and strongly influence air quality. $\mathrm{NO}_{2}$ is a precursor molecule for tropospheric $\mathrm{O}_{3}$ formation. Oxidation of nitrogen oxides $\left(\mathrm{NO}_{\mathrm{x}}=\mathrm{NO}+\mathrm{NO}_{2}\right)$ in the atmosphere results in the formation of nitric acid and aerosol nitrates, causing acid deposition and visibility degradation. $\mathrm{HCHO}$ is the most abundant volatile organic compound (VOC) and produces $\mathrm{HO}_{\mathrm{x}}$ radicals upon photolysis a major oxidizer in the atmosphere, which sustains photochemical production of $\mathrm{O}_{3}$ and secondary organic aerosols (SOA) (Griffin et al., 2004; Volkamer et al., 2010). CHO$\mathrm{CHO}$ also forms $\mathrm{HO}_{\mathrm{x}}$ radicals upon photolysis and is a direct precursor for SOA. Studies conducted in Mexico City have suggested that $\mathrm{CHOCHO}$ could be responsible for 10$15 \%$ of SOA formation in Mexico City (Volkamer et al., 2007). Aerosols directly affect human health and have been linked to increases in morbidity and mortality (Pope III et al., 2009). A total of 52 research flights, each lasting up to $\sim 4 \mathrm{~h}$, were carried out over the two month period (206 flight hours). Flight plans were developed with the scientific objectives of mapping out horizontal and vertical distribution as well as characterizing transport of pollutants and validation of satellite retrievals. As this was the first deployment of this specific instrument pylon, different integration times and EA sequences were explored as well as the LabVIEW acquisition software was updated during the early portion of the campaign for optimization. Spectra were collected with 2 seconds integration time during the second half of the campaign, and all the data presented in this paper are $2 \mathrm{~s}$ data unless otherwise noted. The most commonly used EA sequence included EAs $90^{\circ}$ (zenith), $20^{\circ}, 10^{\circ}, 5^{\circ}, 2^{\circ}, 0^{\circ},-2^{\circ}$, $-5^{\circ},-10^{\circ},-20^{\circ}$ and $-90^{\circ}$ (nadir) with $0^{\circ}$ corresponding to a view parallel to the horizon. The FOV of the telescope at nadir viewing geometry gives a footprint of $\sim 0.55 \mathrm{~km}$ while flying at $4 \mathrm{~km}$ altitude. Typically, nadir spectra were recorded every $12-15 \mathrm{~s}$, corresponding to a horizontal resolution of $\sim 1 \mathrm{~km}$.
Table 1. List of trace gas references used for DOAS analysis.

\begin{tabular}{lll}
\hline No. & Molecule & Reference \\
\hline 1 & $\mathrm{NO}_{2}(220 \mathrm{~K})$ & Vandaele et al. (1998) \\
2 & $\mathrm{NO}_{2}(294 \mathrm{~K})$ & Vandaele et al. (1998) \\
3 & $\mathrm{O}_{3}(223 \mathrm{~K})$ & Bogumil et al. (2003) \\
4 & $\mathrm{O}_{3}(243 \mathrm{~K})$ & Bogumil et al. (2003) \\
5 & $\mathrm{O}_{4}(298 \mathrm{~K})$ & Hermans (2002) \\
6 & $\mathrm{CHOCHO} \mathrm{(298} \mathrm{K)}$ & Volkamer et al. (2005) \\
7 & $\mathrm{HCHO}(298 \mathrm{~K})$ & Meller and Moortgat (2000) \\
8 & $\mathrm{H}_{2} \mathrm{O}$ & Rothman et al. (2005) \\
9 & $\mathrm{O}_{4}$ & Greenblatt et al. (1990) \\
\hline
\end{tabular}

\section{Data analysis}

\subsection{DOAS analysis}

The measured spectra were analyzed for $\mathrm{NO}_{2}, \mathrm{CHOCHO}$, $\mathrm{HCHO}, \mathrm{H}_{2} \mathrm{O}$ and $\mathrm{O}_{4}$ using the DOAS method (Platt and Stutz, 2008) implemented by the WinDOAS software (Fayt and Van Roozendael, 2001). In DOAS, measured spectra are analyzed against a Fraunhofer reference spectrum, and absorption cross sections of different absorbers in the atmosphere are fitted simultaneously in a selected wavelength interval applying a nonlinear least-square fitting routine. A low-order polynomial to account for scattering processes and broadband absorption in the atmosphere as well as broadband instrumental features, a Ring reference spectrum to account for the "filling-in" of Fraunhofer lines due to rotational Raman scattering (Grainger and Ring, 1962), and an additional intensity offset to account for instrumental stray light were also included in the fitting procedure. The Ring spectrum is calculated from the Fraunhofer reference (Bussemer, 1993). The Twin Otter aircraft being an unpressurized aircraft, the pressure in the cabin changed from 1010-665 mbar over a $3.5 \mathrm{~km}$ altitude range for typical flights (e.g., see Fig. 7). The change in the refractive index as well as any pressure differentials that could give rise to a wavelength shift equally affect the Fraunhofer lines and Earth atmospheric absorbers, and are accounted for by including a linear shift of the measurement spectrum during analysis. The observed shifts are up to $0.18 \mathrm{~nm}$ for the TG spectrometer between the spectra taken at the highest and the lowest altitude. A high-altitude $(\sim 4 \mathrm{~km})$ zenith spectrum from a clean, cloud-free region of the same flight was included for the analysis of the individual flight data. The choice of the zenith spectrum as Fraunhofer reference spectrum minimizes the amount of tropospheric absorbers in the reference spectrum, allowing for the detection of trace gases more sensitively. Since measured spectra are analyzed with respect to a reference spectrum, the quantity retrieved from the DOAS analysis is a differential slant column density ( $\mathrm{dSCD}$ ), which is the integrated difference in concentration of the absorber along the light path length with respect to the reference. The trace gas absorption 


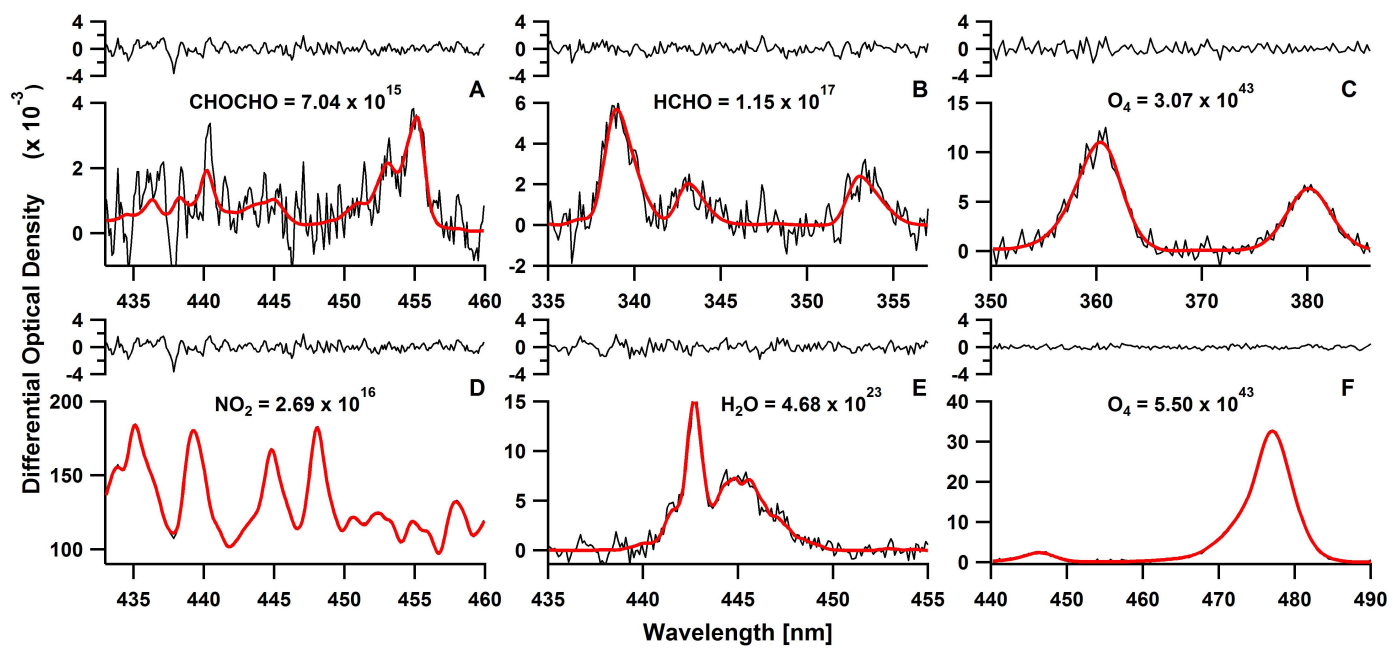

Fig. 4. Spectral proofs for the detection of (A) CHOCHO, (B) HCHO, (C) $\mathrm{O}_{4}$ at $360 \mathrm{~nm}$, (D) $\mathrm{NO}_{2}$, (E) $\mathrm{H}_{2} \mathrm{O}$ and (F) $\mathrm{O}_{4}$ at $477 \mathrm{~nm}$. CHOCHO and $\mathrm{NO}_{2}$ fits are from 14 July 2010 at 22:08 UTC (SZA: $\sim 42^{\circ}$ ) at $\sim 150 \mathrm{~m}$ a.g.l. HCHO and $\mathrm{H}_{2} \mathrm{O}$ fits are from $16 \mathrm{July} 2010$ at 20:19 UTC (SZA: $\sim 24^{\circ}$ ) at $\sim 600 \mathrm{~m}$ a.g.1. $\mathrm{O}_{4}$ fits are from the same flight at 20:11 UTC (SZA: $\sim 23^{\circ}$ ) at $\sim 3000 \mathrm{~m}$ a.g.1. The black lines represent the measured spectra and red lines are fitted reference cross sections. Note that for $\mathrm{NO}_{2}$ and $\mathrm{O}_{4}$ at $477 \mathrm{~nm}$, the absorption is so strong that the black lines are not visible. All the fits are for $0^{\circ}$ EA. The units for retrieved dSCDs for CHOCHO, $\mathrm{HCHO}, \mathrm{NO}_{2}$ and $\mathrm{H}_{2} \mathrm{O}$ are molecules cm ${ }^{-2}$ and for $\mathrm{O}_{4}$ are molecules $\mathrm{cm}^{-5}$.

Table 2. Summary of DOAS analysis settings for different trace gases. 2 Rings (warm and cold) were fitted for $\mathrm{HCHO}$ retrievals, and spectra collected for SZA $<\sim 65^{\circ}$ were only analyzed and hence $\mathrm{BrO}$ was not included in the fit.

\begin{tabular}{lclc}
\hline Trace gas & $\begin{array}{c}\text { Wavelength } \\
\text { range } \\
(\mathrm{nm})\end{array}$ & Fitted absorber & $\begin{array}{c}\text { Polynomial } \\
\text { order }\end{array}$ \\
\hline $\mathrm{NO}_{2}$ & $433-460$ & $1,2,3,6,8,9$ & 3 \\
$\mathrm{CHOCHO}$ & $433-460$ & $1,2,3,6,8,9$ & 3 \\
$\mathrm{HCHO}$ & $335-357$ & $1,2,3,4,5,7$ & 3 \\
$\mathrm{H}_{2} \mathrm{O}$ & $435-455$ & $1,2,4,5,6,8$ & 3 \\
$\mathrm{O}_{4}$ & $350-386$ & $1,2,3,4,5$ & 3 \\
$\mathrm{O}_{4}$ & $440-490$ & $1,2,4,5,8$ & 5 \\
\hline
\end{tabular}

cross sections and other analysis settings for the retrievals of the different trace gases are listed in Tables 1 and 2, respectively. Examples for spectral fits of $\mathrm{NO}_{2}, \mathrm{CHOCHO}, \mathrm{HCHO}$, $\mathrm{O}_{4}$, and $\mathrm{H}_{2} \mathrm{O}$ from the data measured during CalNex and CARES campaigns are shown in Fig. 4. Detection limit for CU AMAX-DOAS instrument in the clean free troposphere (FT) and polluted urban BL such as the SCAB for 30 and $2 \mathrm{~s}$ integration time is listed in Table 3. It is roughly equivalent to the $3 \sigma$ DOAS fit error for typical clean FT (near Rayleigh atmosphere) and polluted urban BL atmospheric conditions (see Fig. 10b for aerosol extinction profile). Note that detection limit highly depends upon the atmospheric conditions during the time of measurement.

We included 2 Ring spectra (Bussemer, 1993), calculated for two different temperatures (298 and $230 \mathrm{~K}$ ), in $\mathrm{HCHO}$
Table 3. Detection limits of CU AMAX-DOAS instrument in the clean free troposphere and the boundary layer in polluted urban conditions like SCAB for different integration times. Detection limit was calculated as $1 \sigma$ RMS detection limit for the aerosol scenario presented in the Fig. 10.

\begin{tabular}{|c|c|c|c|c|}
\hline \multirow[t]{2}{*}{ Trace gas } & \multicolumn{2}{|c|}{$\begin{array}{l}\text { Free troposphere } \\
\qquad(\mathrm{FT})(\mathrm{ppt})\end{array}$} & \multicolumn{2}{|c|}{$\begin{array}{l}\text { Boundary layer } \\
\text { (BL) (ppt) }\end{array}$} \\
\hline & $30 \mathrm{~s}$ & $2 \mathrm{~s}$ & $30 \mathrm{~s}$ & $2 \mathrm{~s}$ \\
\hline $\mathrm{NO}_{2}$ & 5 & 30 & 30 & 120 \\
\hline $\mathrm{CHOCHO}$ & 3 & 16 & 16 & 65 \\
\hline $\mathrm{HCHO}$ & 98 & 290 & 540 & 1355 \\
\hline $\mathrm{H}_{2} \mathrm{O}_{442 \mathrm{~nm}}(\mathrm{ppm})$ & 42 & 210 & 252 & 760 \\
\hline$\varepsilon_{477 \mathrm{~nm}}\left(\mathrm{~km}^{-1}\right)$ & 0.002 & 0.002 & 0.006 & 0.006 \\
\hline$\varepsilon_{360 \mathrm{~nm}}\left(\mathrm{~km}^{-1}\right)$ & 0.004 & 0.004 & 0.012 & 0.012 \\
\hline
\end{tabular}

retrieval to account for the temperature dependence of rotational Raman scattering, which leads to the so-called "ffillingin" of the Fraunhofer lines (Ring effect). The inclusion of a second Ring cross section in the HCHO retrieval (1) improved the $\mathrm{HCHO}$ fit, (2) minimized fitting residuals and (3) reduced scatter in the retrieved HCHO slant columns. A second Ring cross section was not needed to achieve comparable results for other trace gases where the Ring structures are relatively smaller. A new $\mathrm{HCHO}$ reference cross section has recently been reported by Chance and Orphal (2011). We compared the dSCDs retrieved with new cross section to the one from Meller and Moortgat (2000) (used in this work) and found the mean difference of $6.0 \times 10^{14}$ molecules $\mathrm{cm}^{-2}$, which is well below the DOAS fit error for our retrieval. For 
a mean dSCD of $3.0 \times 10^{16}$ molecules $\mathrm{cm}^{-2}$ for $0^{\circ} \mathrm{EA}$ at all flight altitudes for the exemplary flight presented here, the difference is only $2 \%$.

We used the $\mathrm{O}_{4}$ cross section by Greenblatt et al. (1990) for $\mathrm{NO}_{2}$ and $\mathrm{CHOCHO}$ retrievals. The $\mathrm{O}_{4}$ cross section by Hermans (2002) has some nonphysical structures in the baseline around the weak $\mathrm{O}_{4}$ absorption band at $446 \mathrm{~nm}$, which seems to affect $\mathrm{NO}_{2}$ and $\mathrm{CHOCHO}$ fits. The nonphysicality of these structures has been verified by our laboratory (Thalman and Volkamer, 2013). At the time of writing this manuscript, these new $\mathrm{O}_{4}$ reference spectra were subject to ongoing measurements. Hence, for this particular wavelength range, we prefer using Greenblatt et al. (1990).

The quantity retrieved from a DOAS analysis, the dSCD is converted to tropospheric $\mathrm{VCD}\left(\mathrm{VCD}_{\text {trop }}\right)$ by using an air mass factor (AMF). An AMF is a light path enhancement in the atmosphere for a particular viewing geometry relative to vertical path through the atmosphere. The $\mathrm{VCD}_{\text {trop }}$ is the integral absorber concentration per unit area in the troposphere.

$\mathrm{VCD}_{\text {trop }}=\frac{\mathrm{dSCD}}{\mathrm{dAMF}}$

dAMF (differential air mass factor) is usually calculated with the help of a radiative transfer program to convert the measured dSCD to a $\mathrm{VCD}_{\text {trop }}$ and is a difference in AMF between the measured and the reference viewing geometry. It requires a priori knowledge of trace gas vertical concentrations and aerosol extinction coefficients along with other input parameters such as pressure, temperature, surface albedo (SA), aerosol asymmetry parameter $g$, and aerosol single scattering albedo (SSA). $\mathrm{NO}_{2}$ concentrations, profile shapes and aerosol scenarios are highly variable in the SCAB because of the variable sources and hence could result in a significant amount of error in radiative transfer calculations of AMFs. Instead, we applied a simple geometric approximation for the nadir viewing geometry to convert dSCDs to VCDs. The geometric approach, its validity and error associated with this approximation are further discussed in Sect. 3.3.

\subsection{Radiative transfer modeling}

Since the AMAX-DOAS measurements are carried out in the open atmosphere using scattered sun light as the light source, the solar radiative transfer during the time of measurement needs to be modeled to interpret the retrieved data. The radiative transfer program McArtim (Monte Carlo atmospheric radiative transfer inversion model) (Deutschmann et al., 2011) used here is a fully spherical model and simulates radiative transfer in the atmosphere in the UV/vis/NIR spectral range using a Monte Carlo approach. In McArtim the 3-D atmosphere is simulated as a 1-D modeled atmosphere divided into concentric spherical shells. The atmospheric conditions during the time of measurement in each vertical layer are assumed to be horizontally and vertically homogeneous. McArtim has the capability to simulate Jacobians of trace gases and aerosols needed for the interpretation of AMAX-DOAS data. Auxiliary input parameters used in the radiative transfer program were either measured aboard the aircraft (i.e., SA), on the ground at the CalNex ground site (Ryerson et al., 2013) (i.e., aerosol SSA), at the California Air Resources Board (CARB) (http://www.arb.ca.gov/ homepage.htm) monitoring stations or based on values from previous studies for urban environments (i.e., g-parameter, e.g., Dubovik et al., 2002).

\subsection{Geometric approximation for conversion of dSCDs to VCDs}

Under the geometric approximation, it is assumed that all the photons get scattered only once very close to the ground or are reflected from the surface before entering the telescope in nadir geometry. The geometric air mass factor (geoAMF) is then only a function of the solar zenith angle (SZA) and is given by

geoAMF $=1+\frac{1}{\cos (\mathrm{SZA})}$.

The schematic of the geometric approximation is shown in the Fig. 1 inset.

In our DOAS analysis, a high-altitude zenith spectrum from a clean background area is used as reference spectrum. Assuming this background zenith spectrum has no tropospheric $\mathrm{NO}_{2}$, the nadir dSCDs can be considered as tropospheric slant column densities (SCDs) for most flights performed at low SZA. At high SZA, stratospheric $\mathrm{NO}_{2}$ contribution changes with SZA and hence requires independent removal. For such flights (18 out of 52), stratospheric $\mathrm{NO}_{2}$ contribution was corrected by fitting a polynomial through all the zenith dSCDs above $1.8 \mathrm{~km}$ flight altitude and subtracting the polynomial from the nadir measurements. The resulting quantity is defined as the tropospheric SCDs. This quantity is then converted to $\mathrm{VCD}_{\text {trop }}\left(\mathrm{VCD}_{\text {trop }}=\mathrm{SCD}_{\text {trop }} /\right.$ geoAMF$)$, and is defined as VCD below the aircraft.

Sensitivity studies using the radiative transfer model (RTM) McArtim were performed to estimate uncertainties associated with the geometric approximation. A range of conditions that could potentially occur during the time of measurements were explored for this study. A representative sample of the results is summarized in Table 4, where the relative error in the geoAMF assumption compared to AMFs calculated using the RTM for different scenarios are specified. The results for most likely atmospheric state in the SCAB (surface albedo, $\mathrm{SA}=0.1$; single scattering albedo, $\mathrm{SSA}=0.94$; asymmetry parameter, $g=0.68$; aerosol optical depth, $\mathrm{AOD}=0.4$; boundary layer height, $\mathrm{BLH}=1.0 \mathrm{~km}$; $\mathrm{NO}_{2}$ mixing ratio $=10 \mathrm{ppb}$ ) is also shown in Table 4; it is based on ancillary measurements aboard the aircraft, CalNex ground site at Pasadena and CARB ground monitoring stations or climatology of urban aerosol. Thomson et al. (2012) reported an average value for SSA of 0.92 at $532 \mathrm{~nm}$ during the entire CalNex campaign at Pasadena. They found SSA 
Table 4. Relative error of geometric approximation compared to AMF calculated for nadir viewing geometry at $455 \mathrm{~nm}$ using radiative transfer program McArtim under different scenarios.

\begin{tabular}{|c|c|c|c|c|c|c|c|c|c|c|c|c|}
\hline \multirow[t]{2}{*}{$\begin{array}{l}\text { Altitude } \\
{[\mathrm{km}]}\end{array}$} & \multirow[t]{2}{*}{$\begin{array}{c}\text { Solar } \\
\text { zenith } \\
\text { angle }(\mathrm{SZA})\end{array}$} & \multirow[t]{2}{*}{$\begin{array}{c}\text { Most } \\
\text { probable } \\
\text { conditions* }\end{array}$} & \multicolumn{2}{|c|}{$\begin{array}{c}\text { Boundary layer } \\
\text { height [m] }\end{array}$} & \multicolumn{2}{|c|}{$\begin{array}{c}\mathrm{NO}_{2} \\
\text { concentration } \\
{[\mathrm{ppb}]}\end{array}$} & \multicolumn{2}{|c|}{$\begin{array}{c}\text { Surface albedo } \\
\text { (SA) }\end{array}$} & \multicolumn{2}{|c|}{$\begin{array}{c}\text { Single } \\
\text { scattering } \\
\text { albedo (SSA) }\end{array}$} & \multicolumn{2}{|c|}{$\begin{array}{c}\text { Aerosol optical } \\
\text { depth (AOD) }\end{array}$} \\
\hline & & & 500 & 1500 & 5 & 20 & 0.05 & 0.15 & 0.90 & 0.99 & 0.10 & 0.80 \\
\hline \multirow[t]{3}{*}{2 (low) } & 20 & 6.3 & 3.3 & 9.0 & 7.2 & 5.6 & 3.0 & 12.2 & 4.4 & 9.6 & 4.3 & 6.7 \\
\hline & 40 & 4.7 & 1.0 & 5.6 & 5.1 & 3.2 & 5.7 & 9.4 & 1.1 & 6.9 & 2.9 & 2.6 \\
\hline & 60 & 5.9 & 7.3 & 6.3 & 6.0 & 7.0 & 15.3 & 0.7 & 8.0 & 3.3 & 3.4 & 11.0 \\
\hline \multirow{2}{*}{3.5 (high) } & 40 & 5.4 & 8.6 & 3.1 & 4.1 & 5.1 & 15.9 & 2.8 & 7.6 & 2.1 & 6.9 & 4.9 \\
\hline & 60 & 16.1 & 16.4 & 14.0 & 14.5 & 16.5 & 25.0 & 8.3 & 17.5 & 11.6 & 14.2 & 19.3 \\
\hline
\end{tabular}

* Most probable atmospheric conditions in SCAB: surface albedo $=0.10$, single scattering albedo $=0.94, g$ parameter $=0.68$, aerosol optical depth $=0.4$, boundary layer height $=1$ km and $\mathrm{NO}_{2}$ mixing ratio $=10.0 \mathrm{ppb}$.

values to be slightly higher during the day time, when our measurements were taken. AOD measured at the AERONET station at Pasadena showed AOD values to be lower than 0.4 at $440 \mathrm{~nm}$ for almost all of summer 2010, and the AOD of 0.4 likely represents an upper limit to provide a conservative estimate of relative error. The value of asymmetry parameter $g$ is based on the climatology of urban aerosol (e.g., Dubovik et al., 2002) and agrees well with measurements at the AERONET station at Pasadena (range for the entire campaign: 0.63-0.80). AMFs calculated for this range of $g$ values were within $3 \%$ of AMF relative to $g=0.68$. It should be noted that these quantities are wavelength dependent. The largest source of error was found to be SA (see Table 4), which is constrained using the measurement aboard the aircraft. Notably, our SA measurements also provide means to filter data for conditions where the error may exceed $10 \%$. The error from using the geoAMF compared to AMF calculated for most likely atmospheric state in SCAB is plotted as a function of SZA in Fig. 5. Based on this a SZA cutoff of $65^{\circ}$ was used to constrain the error in the $\mathrm{NO}_{2}$ vertical columns. With these filters the error in geoAMF is $<7 \%$ for most conditions ( $85 \%$ of flight time with SZA $<65^{\circ}$ ), and slightly larger (error $<25 \%$ in all cases) for SZA $\sim 65^{\circ}$ or during high-altitude flights over low SA. The error associated with the geoAMF is consistent with previous airborne DOAS studies that used the geometric approximation. Melamed et al. (2003) estimated the error in $\mathrm{NO}_{2} \mathrm{VCD}$ from the geometric approximation to be $\sim 20 \%$ based on the discrepancies between measured and modeled $\mathrm{O}_{2}$ AMF. To the best of our knowledge, there have been no previous deployments of AMAX-DOAS with simultaneous SA measurements by independent sensors. The high SA value of $\sim 10 \%$ at $477 \mathrm{~nm}$ is found widespread in the SCAB, and has the favorable effect of reducing errors from the geoAMF assumption due to compensating effects in the radiative transfer calculations.

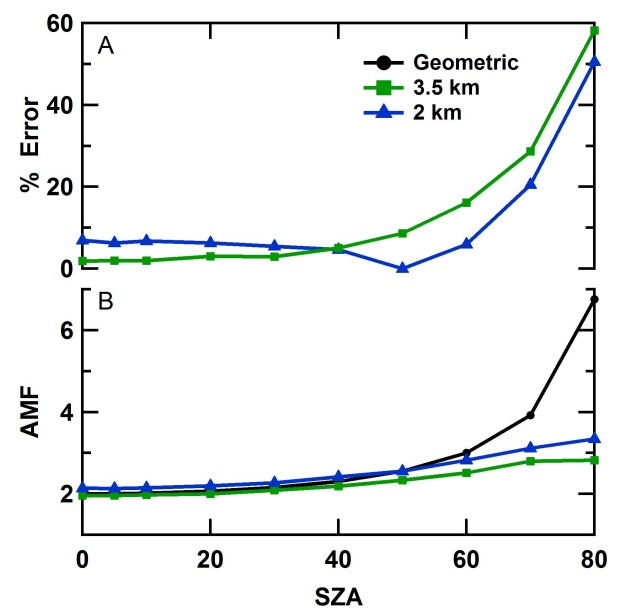

Fig. 5. (A) Relative error of geometric air mass factor (geoAMF) compared to AMF for nadir geometry calculated using RTM, McArtim for flight altitude of $3.5 \mathrm{~km}$ (green) and $2 \mathrm{~km}$ (blue) a.g.l., for most likely atmospheric conditions in South Coast Air Basin (SCAB). (B) AMF calculated using McArtim (green and blue) and geoAMF (black). Most likely atmospheric state in SCAB: surface albedo $=0.10$, single scattering albedo $=0.94, g$ parameter $=0.68$, aerosol optical depth $=0.4$, boundary layer height $=1 \mathrm{~km}$ and $\mathrm{NO}_{2}$ mixing ratio $=10.0 \mathrm{ppb}$.

\subsection{Aerosol extinction profile retrieval}

In the near-UV and visible wavelength range, under cloud free conditions, the change in photon path length compared to the Rayleigh atmosphere and hence the measured dSCDs of a trace gas depend mainly on the aerosol extinction profile. Thus, if the vertical distribution of an absorber is well known, the dSCD measurements of such species can be exploited to infer aerosol properties. The collisional complex of oxygen $\mathrm{O}_{4}$ is one such species (Hönninger et al., 2004; Wagner et al., 2004; Wittrock et al., 2004; Clémer et al., 2010). The $\mathrm{O}_{4}$ concentration varies with the pressure, temperature and square of 
the concentration of $\mathrm{O}_{2}$. Hence, the dSCD measurements of $\mathrm{O}_{4}$ can be used to calculate the aerosol extinction profiles. $\mathrm{O}_{4}$ dSCD measurements from ground-based and airborne MAXDOAS have previously been used for aerosol extinction profile and AOD retrievals (Clémer et al., 2010; Merlaud et al., 2011 and references within). Aerosol inversion is a nonlinear problem and hence requires an iterative method. We used an iterative forward model approach to obtain the aerosol extinction profile. Under this approach a set of measured $\mathrm{O}_{4}$ SCDs, $\boldsymbol{y}$, is related to the aerosol extinction vertical profile, $\boldsymbol{x}_{i}$, by forward model $\mathbf{F}$ such that

$\boldsymbol{y}=\mathbf{F}\left(\boldsymbol{x}_{i}, \boldsymbol{b}\right)+\varepsilon$,

where $\boldsymbol{b}$ are forward model parameters that are not retrieved, $i$ represents the iteration index, and $\varepsilon$ is the sum of measurement and model error. For $0^{\circ}$ EA, i.e., parallel to the horizon, under cloud free conditions, the measurement is almost entirely sensitive to the altitude of measurement and nearly all of the vertical information contained in the SCD comes from that particular altitude. We exploit this property and retrieve the aerosol extinction profile by using a modified onion peeling algorithm using $0^{\circ} \mathrm{EA} \mathrm{O}_{4} \mathrm{SCD}$ measurements. First the extinction above the highest altitude is constrained using upward EA scans performed at that altitude. Then the aerosol extinction values at the subsequent altitudes during the descent are determined iteratively using the set of $0^{\circ}$ EA $\mathrm{O}_{4} \mathrm{SCD}$ measurements at those altitudes. Aerosol extinction below the lowest aircraft altitude is obtained using downward EA scans performed at the lowest altitude. This process is repeated to account for any information on $\mathrm{O}_{4}$ SCDs for $0^{\circ}$ EA at a given altitude from the $\mathrm{O}_{4}$ column below the measurement altitude, until measured and modeled $\mathrm{O}_{4} \mathrm{SCDs}$ agree. The profile is then verified using other angles in the EA scans during the descent/ascent. It should be noted that this approach is feasible only due to the ability to maintain the desired EAs within a narrow error bound also during descent/ascent of the aircraft, as discussed in Sect. 2.5.

The relative error in $\mathrm{O}_{4}$ SCDs at different altitudes in the atmosphere for different pointing uncertainties for a $0^{\circ} \mathrm{EA}$ is illustrated in Fig. 6. An uncertainty of $1-2^{\circ}$ in pointing accuracy, which can easily happen on an airborne platform, could result in 20-80\% $\mathrm{O}_{4} \mathrm{SCD}$ error above $10 \mathrm{~km}$. Even though the $\mathrm{O}_{4}$ concentration is very small above $10 \mathrm{~km}$ (around $10 \%$ of the near surface at $10 \mathrm{~km}$ ), the SCD at $0^{\circ}$ EA can still be measured with good signal-to-noise because of the much longer photon path lengths in the less-dense air. Hence, the high sensitivity towards the pointing accuracy is the limiting source of error. Considering a nonlinear relationship between $\mathrm{O}_{4} \mathrm{SCD}$ and aerosol extinction, this could result in even larger errors when $\mathrm{O}_{4}$ SCDs are used to retrieve the aerosol extinction profile. This highlights the need for a motion compensation system to maintain pointing accuracy of the telescope.
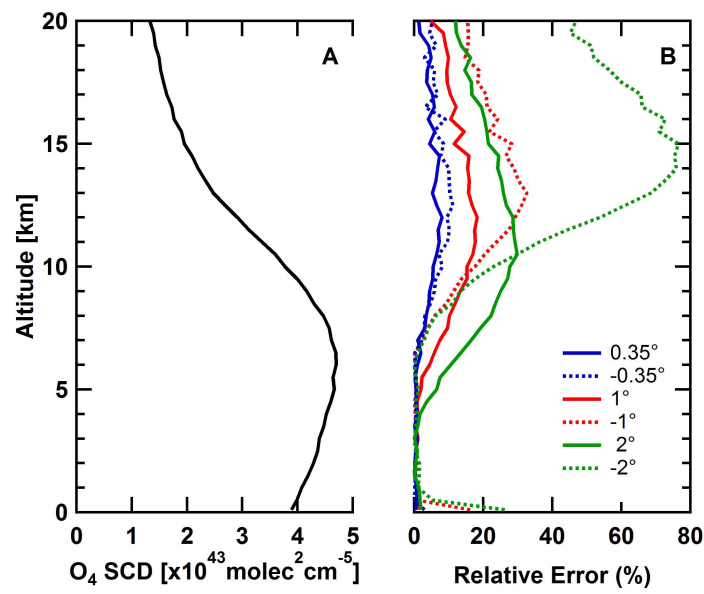

Fig. 6. (A) Vertical profile of $\mathrm{O}_{4}$ SCDs calculated for $0^{\circ}$ EA at $477 \mathrm{~nm}$ using McArtim (US standard atmosphere with exponential aerosol extinction profile with extinction of $0.2 \mathrm{~km}^{-1}$ at the ground and $2.5 \mathrm{~km}$ scale height). (B) Relative error in $\mathrm{O}_{4} \mathrm{SCDs}$ for $0.35^{\circ}$ (blue), $1^{\circ}$ (red) and $2^{\circ}$ (green) pointing error of the telescope at $0^{\circ}$ EA. The solid and dashed lines represent angles above and below the horizon, respectively.

\subsection{Trace gas vertical profile retrieval}

The trace gas vertical profile retrieval algorithm is based on the concept of optimal estimation (Rodgers, 2000). The use of this technique for profile retrieval from AMAX-DOAS measurements has been described in detail before (e.g., Bruns et al., 2004) and hence will only be introduced here briefly. A set of measurements, $\boldsymbol{y}$, which in our case are trace gas SCDs for different LOS can be related to a vertical distribution, $\boldsymbol{x}$, by the forward model $\mathbf{F}$ as shown in Eq. (3). Considering that we use a high-altitude clean-environment zenith reference spectrum, SCD of the reference spectrum is/can be considered to be negligible for tropospheric pollutants.

Equation (3) can be rewritten in a linearized form as

$\boldsymbol{y}=\mathbf{K} \boldsymbol{x}+\varepsilon$,

where $\mathbf{K}$ defined as $\frac{\partial \mathrm{SCD}_{i}}{\boldsymbol{x}_{i}}$ is the weighting function matrix that expresses the sensitivity of measurement $\boldsymbol{y}$ to $\boldsymbol{x}$. We used the maximum a posterior solution as described in Rodgers (2000) to solve Eq. (4):

$\boldsymbol{x}=\boldsymbol{x}_{\mathrm{a}}+\left(\mathbf{K}^{T} \mathbf{S}_{\varepsilon}^{-1} \mathbf{K}+\mathbf{S}_{\mathrm{a}}\right)^{-1} \mathbf{K}^{T} \mathbf{S}_{\varepsilon}^{-1}\left(\boldsymbol{y}-\mathbf{K} \boldsymbol{x}_{\mathrm{a}}\right)$,

where $\boldsymbol{x}_{\mathrm{a}}$ is the a priori profile and $\mathbf{S}_{\mathrm{a}}$ and $\mathbf{S}_{\varepsilon}$ are the a priori error and measurement error covariance matrices, respectively. The a priori profile is used to constrain the above described problem as it is generally ill-posed. $\mathbf{S}_{\varepsilon}$ was constructed using the square of the DOAS fit error as the diagonal elements of the matrix, the nondiagonal elements were set to 0 . The apriori error covariance matrix, $\mathbf{S}_{\mathrm{a}}$, was used as a 
tuning parameter, maximizing the information content while avoiding spurious oscillations in retrieved profiles (Schofield et al., 2004). The nondiagonal elements in $\mathbf{S}_{\mathrm{a}}$ matrix accounts for correlation of trace gas values between different altitude layers and were included as the Gaussian function shown in Eq. (5) (Barret et al., 2002; Hendrick et al., 2004):

$\mathbf{S}_{\mathrm{a}_{i j}}=\sqrt{\mathbf{S}_{\mathrm{a}_{i i}} \mathbf{S}_{\mathrm{a}_{j j}} \exp \left((-\ln 2)\left(\frac{z_{i}-z_{j}}{\gamma}\right)^{2}\right)}$,

where $z_{i}$ and $z_{j}$ are the altitudes of the $i$-th and $j$-th layers respectively and $\gamma$ is the half width at half maximum (HWHM). The value of $\gamma$ was set to half the width of vertical grid considered for inversion (Hendrick et al., 2004).

The solution given by Eq. (5) is a weighted mean of the a priori profile and the information from the measurement. This weight is given by the averaging kernel matrix $\mathbf{A}$

$\mathbf{A}=\left(\mathbf{K}^{T} \mathbf{S}_{\varepsilon}^{-1} \mathbf{K}+\mathbf{S}_{\mathrm{a}}\right)^{-1} \mathbf{K} \mathbf{T} \mathbf{S}_{\varepsilon}^{-1} \mathbf{K}$.

The retrieval at any layer is an average of the whole profile weighted by the row of the averaging kernel matrix corresponding to that layer. The averaging kernel matrix also contains information about the number of independent pieces of information retrieved, and an estimate of the vertical resolution of the retrieved profile at a given level. The trace of the averaging kernel matrix, $\mathbf{A}$, gives the DOF, i.e., number of independent pieces of information retrieved. The FWHM of the main peak of an averaging kernel at any layer gives the estimate of the vertical resolution of the retrieved profile at that layer. For an ideal retrieval scenario, $\mathbf{A}$ is an identity matrix, the DOF equals the number of retrieved profile layers, and the averaging kernels peak at their corresponding altitudes. In reality, the retrieved profile is a smoothed version of the true profile.

EA scans at flight altitude can be used to retrieve vertical profiles (e.g., Bruns et al., 2004), but the sensitivity of such scans are limited to mostly $2 \mathrm{~km}$ above and below the plane. Box AMF calculations for EAs $5^{\circ}$ and $10^{\circ}$ above and below the horizon show that the sensitivity of these EAs falls below $50 \%$ of the peak value above and below $2 \mathrm{~km}$ of the aircraft. Roscoe and Hill (2002) showed that vertical resolution can be improved by oversampling, provided that the random error is degraded. Sensitivity can be improved by combining EA scan with aircraft ascent/descent. We exemplarily present vertical profiles from actively controlled EA scans during an aircraft descent at Brackett airfield in the Los Angeles Basin, CA.

\subsection{Error analysis}

Measurement noise, forward model parameter (e.g., SA) uncertainties and smoothing error due to finite resolution of the inversion grid contribute to the uncertainties in the retrieved profiles. The actual model error itself is neglected here as
Table 5. Uncertainty in aerosol extinction coefficient due to uncertainty in model input parameters.

\begin{tabular}{lll}
\hline Parameter & $\begin{array}{l}\text { Uncertainty } \\
\text { in parameter }\end{array}$ & $\begin{array}{l}\text { Uncertainty } \\
\text { in extinction } \\
\text { coefficient }\end{array}$ \\
\hline Surface albedo & \pm 0.05 & $<2 \%$ \\
Single scattering albedo & \pm 0.05 & $<2 \%$ \\
Asymmetry parameter & \pm 0.07 & up to $10 \%$ \\
Temperature & $\pm 5^{\circ} \mathrm{C}$ & up to $10 \%$ \\
Pointing accuracy & $\pm 0.35^{\circ}$ & mostly in transition layer \\
\hline
\end{tabular}

these uncertainties are very small (Hendrick et al., 2006; Wagner et al., 2007). Thus, the total error in the retrieved profile is given by

$\mathbf{S}_{\text {total }}=\mathbf{S}_{\mathrm{m}}+\mathbf{S}_{\mathrm{f}}+\mathbf{S}_{\mathrm{s}}$

where $\mathbf{S}_{\mathrm{m}}$ is retrieval noise covariance, $\mathbf{S}_{\mathrm{f}}$ is forward model parameter covariance, and $\mathbf{S}_{\mathrm{s}}$ is smoothing error covariance matrices. Since the a priori covariance matrix $\mathbf{S}_{\mathrm{a}}$ is used as a tuning parameter, the smoothing error is also not considered, but could be estimated from the averaging kernel matrix $\mathbf{A}$.

The error due to measurement noise is given by the retrieval noise covariance

$\mathbf{S}_{\mathrm{m}}=\mathbf{G}^{T} \mathbf{S}_{\varepsilon}^{-1} \mathbf{G}$

where

$\mathbf{G}=\left(\mathbf{K}^{T} \mathbf{S}_{\varepsilon}^{-1} \mathbf{K}+\mathbf{S}_{\mathrm{a}}\right)^{-1} \mathbf{K} \mathbf{T} \mathbf{S}_{\varepsilon}^{-1}$

is the gain matrix and expresses the sensitivity of retrieved profile to measured SCDs.

Sensitivity studies were performed in order to estimate the error in the retrieved profiles due to uncertainties in forward model parameters including EA accuracy. For each forward model parameter, $\boldsymbol{b}$, we retrieved a new profile, $\boldsymbol{x}^{\prime}$, such that

$\boldsymbol{y}=\mathbf{F}\left(\boldsymbol{x}^{\prime}, \boldsymbol{b}^{\prime}\right)$,

where $\boldsymbol{b}^{\prime}$ is the perturbation to the forward model parameter b.

The difference between retrieved profiles $x$ with forward model parameter $\boldsymbol{b}$, and $\boldsymbol{x}^{\prime}$ with $\boldsymbol{b}^{\prime}$, gives an estimate of the forward model error caused by uncertainties in parameter $\boldsymbol{b}$. The square of the differences constitutes the diagonal element of the corresponding forward model parameter covariance matrix $\mathbf{S}_{\mathrm{f}}$.

We studied the effects of uncertainties in SA, SSA, asymmetry parameter, temperature, and EA on aerosol extinction coefficients at $477 \mathrm{~nm}$. Results from the study are summarized in Table 5 . The asymmetry parameter uncertainty $(g=0.68 \pm 0.07)$ could result in as much as $10 \%$ relative error in extinction values. A $5{ }^{\circ} \mathrm{C}$ temperature uncertainty 
could also result in similar relative error as the $\mathrm{O}_{4}$ concentration in the atmosphere is temperature dependent (density effect). We used temperature measured aboard the aircraft to minimize this error. Angle accuracy uncertainty was found to result in large extinction errors $\left(>0.01 \mathrm{~km}^{-1}\right)$ in the transition layer at the top of the boundary layer and around elevated layers. It points to the possibility of uncertainty in altitude of aerosol layers in the extinction profile and results in a blurring effect (Kritten et al., 2010). Angle accuracy uncertainties are often not considered for error estimates for vertical profiles from airborne DOAS measurements, but it could be the most important and largest source of error in the retrieved profiles, especially for transition layers. The error bars in the aerosol extinction profile (Fig. 10b) reflect uncertainty due to measurement error, and uncertainty in SSA, $g$ parameter, SA and EA.

Uncertainties in aerosol extinction coefficients and EA were only considered as a forward model parameter affecting the retrieved trace gas profiles as other forward model parameters (e.g., SA) have already been considered in aerosol extinction coefficient retrieval.

\section{Results and discussion}

\subsection{Nadir observations}

\subsubsection{Horizontal distribution of $\mathrm{NO}_{2}$}

As an example, a map of $\mathrm{NO}_{2} \mathrm{VCD}$ distribution in the $\mathrm{SCAB}$ from RF\#46 on 16 July 2010 (10:30-14:10 PDT) is shown in Fig. 7 . The small footprint $(\sim 1 \mathrm{~km}$ along the flight track) of the measurement allows us to clearly identify local hotspots and pollution sources. The $\mathrm{NO}_{2}$ map in Fig. 7 reflects our understanding of the $\mathrm{NO}_{\mathrm{x}}$ sources and its relatively short life time $(\sim 4 \mathrm{~h})$. Clear $\mathrm{NO}_{2}$ hotspots can be observed around downtown Los Angeles and Ontario, along the major highway, State Route 210, and at intersections of major highways. In contrast, very little $\mathrm{NO}_{2}$ is seen in the eastern part of the basin, and over the High Desert to the northeast, where there are no significant local sources of $\mathrm{NO}_{\mathrm{x}}$. The footprint of CU AMAX-DOAS is comparable to air quality models, and smaller than that of current solar stray light satellite observations, which also measure VCDs of trace gases; this makes this data set an excellent opportunity to evaluate emissions in air quality models and validate satellite observations. A first application of CU AMAX-DOAS to test NASA $\mathrm{NO}_{2} \mathrm{VCD}$ retrievals from the OMI/AURA satellite instrument is currently under review (Oetjen et al., 2013).

\subsubsection{Validation of $\mathrm{NO}_{2}$ vertical column}

To validate the retrieval of our $\mathrm{NO}_{2}$ VCDs by CU AMAXDOAS using the geometric approximation, we compared our observations with $\mathrm{NO}_{2}$ VCDs from ground-based MAXDOAS instruments. Two MAX-DOAS instruments (Sinreich et al., 2010; Coburn et al., 2011) were deployed at the CalNex ground site (Ryerson et al., 2013) in Pasadena, the Fontana Arrows CARB monitoring network station and the CARES T1 (Zaveri et al., 2012) site in Cool, CA at various times of the campaign. MAX-DOAS operates on the same principle as AMAX-DOAS. Spectra measured at off-axis angles were analyzed for $\mathrm{NO}_{2}$ using a closest zenith reference spectrum in time. The retrieved $\mathrm{NO}_{2} \mathrm{dSCDs}$ for $20^{\circ} \mathrm{EA}$ were converted to VCDs using a dAMF calculated by McArtim. This EA was chosen to minimize the effect of uncertainties in model parameters - especially magnitude and shape of $\mathrm{NO}_{2}$ profile and aerosols. Sensitivity studies were performed to estimate the error in calculated dAMF due to model parameter uncertainties and is estimated to be around $8 \%$. Considering $\sim 3 \% \mathrm{dSCD}$ retrieval error and $\sim 8 \% \mathrm{dAMF}$ error, we estimate the overall error in MAX-DOAS VCDs to be around $10 \%$. Further details about MAX-DOAS measurements during the CalNex and CARES campaigns can be found in Ortega et al. (2013). MAX-DOAS instruments at Pasadena and Fontana Arrows were pointing in both east and west directions, while the one at the CARES T1 site was facing both north and south. Those MAX-DOAS instruments are capable of making a full $180^{\circ}$ EA scan.

The NOAA Twin Otter was frequently routed over these ground sites. The correlation plot between the CU AMAXDOAS and MAX-DOAS instruments is shown in Fig. 8. Correlations showed sensitivity to filtering data by criteria such as the distance of the plane and ground site, the relative azimuth angle between plane heading and ground viewing, and inhomogeneous air mass. The inhomogeneity of air mass was measured by MAX-DOAS, which observed differences in $\mathrm{NO}_{2}$ VCDs in the east and west view of up to $2.5 \times 10^{16}$ molecules $\mathrm{cm}^{-2}$. Figure 7 gives an idea of the $\mathrm{NO}_{2}$ VCD variability as mapped by CU AMAX-DOAS. Filtering for data within $5 \mathrm{~km}$ radius of the ground site, clouds (via two webcams installed on the aircraft), SZA $<65^{\circ}$ aircraft altitude $<4 \mathrm{~km}$, and $<1.5 \times 10^{16}$ molecules $\mathrm{cm}^{-2}$ $\mathrm{NO}_{2}$ VCD difference in east/west view of MAX-DOAS instruments in $\mathrm{SCAB}$, as well as coincident measurements within $10 \mathrm{~min}$ of the aircraft overpass, resulted in a correlation with slope of $0.86 \pm 0.03$, and offset in VCD of $-0.8 \pm 3.7 \times 10^{14}$ molecules $\mathrm{cm}^{-2}\left(R^{2}=0.96\right)$ (grey dots in Fig. 8). The slope of the linear fit line is skewed by the measurements at CARES T1 site that are near or below the detection limit of both the instruments, but nevertheless still a very good agreement between the two instruments. If only measurements in SCAB are considered, and filtering is further constrained (relative azimuth angle between plane heading and ground viewing $< \pm 15^{\circ}$, and variability in $\mathrm{NO}_{2} \mathrm{VCD}$ for both instruments $<8 \times 10^{15}$ molecules $\mathrm{cm}^{-2}$ ), the slope increases to $0.95 \pm 0.09$, offset in VCD of $2.5 \pm 1.4 \times 10^{15}$ molecules $\mathrm{cm}^{-2}\left(R^{2}=0.86\right)$ (Fig. 8). This sensitivity to filtering criteria reflects upon the inhomogeneity of the SCAB air mass and also points to the validity 

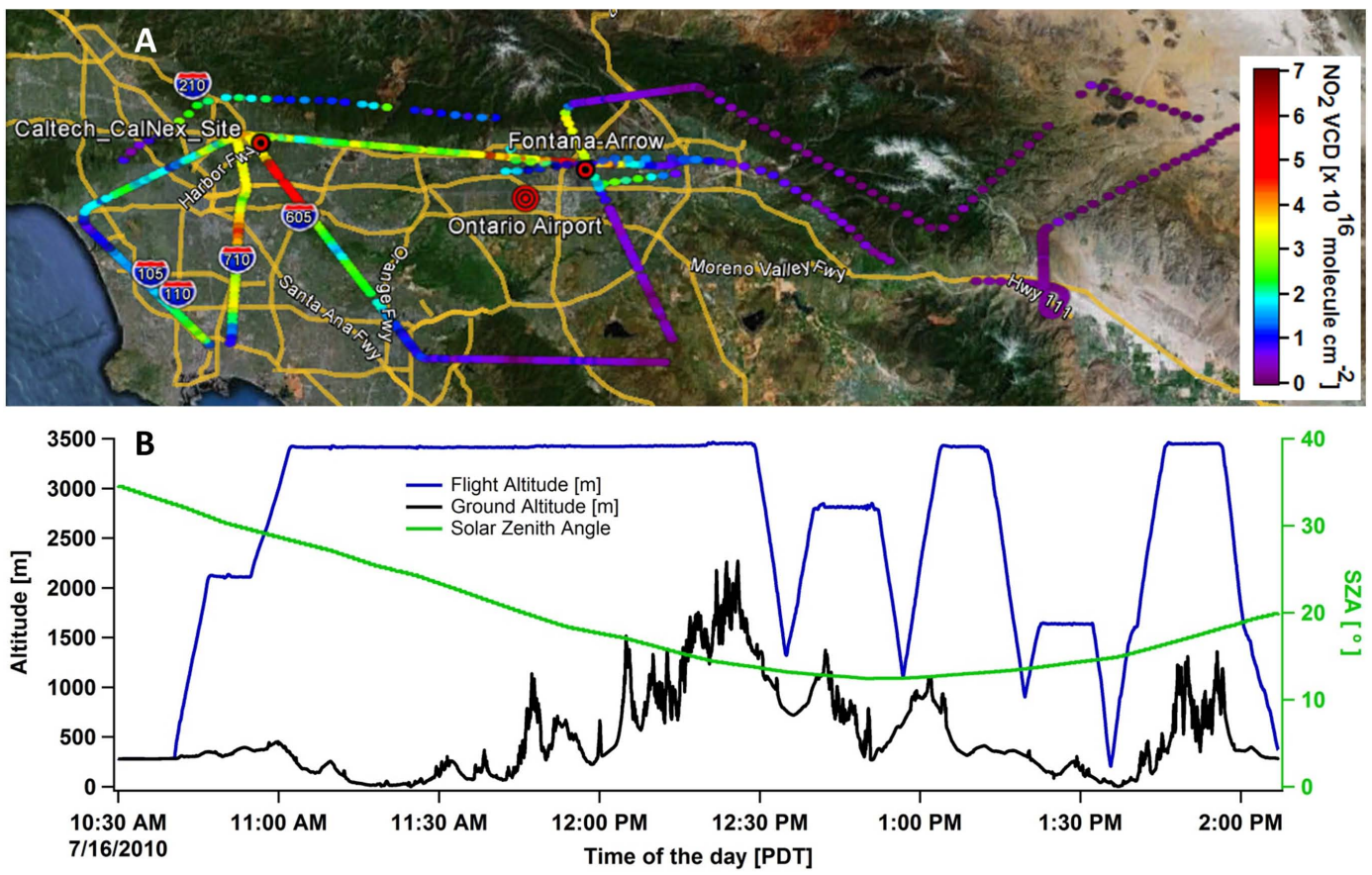

Fig. 7. (A) Map showing horizontal distribution of $\mathrm{NO}_{2}$ VCDs below the aircraft derived from nadir measurements from $\mathrm{RF} 446$ on 16 July 2010 (10:30-14:10 PDT - Pacific Daylight Time) in the SCAB. MAX-DOAS instruments deployment sites and the base airport for the Twin Otter are shown as red targets. (B) Time trace of flight altitude (blue), ground altitude (black) and SZA (green) from the same flight.

of geometric approach under horizontally inhomogeneous conditions.

\subsection{Limb observations}

Vertical profiles of aerosol extinction coefficient and trace gas concentrations were retrieved for a low approach at Brackett airfield, CA during RF\#46. The aircraft was flying at $\sim 3.1 \mathrm{~km}$ a.g.l. (above ground level), made a slow descent to an altitude of $\sim 0.6 \mathrm{~km}$ a.g.l. at the airport, and then ascended again. The telescope was scanning a set of EAs $\left(-90^{\circ},-5^{\circ},-2^{\circ}, 0^{\circ}, 2^{\circ}, 5^{\circ}, 90^{\circ}\right)$ during the low approach. A complete set of EAs was also measured at the highest altitude just before the descent and at the lowest point before starting to ascend in order to characterize the air mass above and below the aircraft. The descent portion of the low approach took $\sim 8 \mathrm{~min}$. Low approach is a maneuver over an airport in which the pilot intentionally does not make contact with the runway.

\subsubsection{Determination of $\mathrm{O}_{4} \mathrm{SCD}$ in the reference spectrum}

The scale height of $\mathrm{O}_{4}$ in the atmosphere is $\sim 4 \mathrm{~km}$ and as our measurements were usually performed below $4 \mathrm{~km}$ altitude, it is important to quantify the $\mathrm{O}_{4} \mathrm{SCD}$ contained in the reference spectrum $\left(\mathrm{SCD}_{\text {ref }}\right)$ in order to accurately retrieve the aerosol extinction profile. Merlaud et al. (2011) used a linear regression between measured $\mathrm{dSCD}$ and calculated SCD for airborne measurements above $5.5 \mathrm{~km}$ in the Arctic to determine $\mathrm{SCD}_{\text {ref }}$ and the dSCD correction factor, $\alpha$ :

$\mathrm{SCD}=\alpha \times \mathrm{dSCD}+\mathrm{SCD}_{\text {ref }}$

The dSCD correction factor $(\alpha)$ has been used to scale measured $\mathrm{O}_{4}$ dSCDs to bring inferences of aerosol extinction into agreement with other sensors, such as AERONET (e.g., Clémer et al., 2010). It is an empirical observation that some MAX-DOAS applications find measured $\mathrm{O}_{4} \mathrm{dSCDs}$ to be too large compared to modeled $\mathrm{O}_{4}$ dSCDs for a Rayleigh atmosphere. The nonphysicality of $\alpha$, different from unity, is a subject of ongoing debate in the DOAS community. For example, the value for the correction factor is different between different environments and research groups, wavelength, and ranges from 0.75 to 0.89 (Wagner et al., 2009; Clémer et al., 2010; Merlaud et al., 2011; Zieger et al., 2011). It has been speculated that the need for $\alpha$ could be due to the temperature dependence of the $\mathrm{O}_{4}$ absorption cross section (Wagner et al., 2009; Cleémer et al., 2010). Indeed, a temperature uncertainty in the $\mathrm{O}_{4}$ absorption cross section has been reported (Blickensdorfer and Ewing, 1969; Wagner et al., 2002 and references within).

We employed the same approach as Merlaud et al. (2011) to determine $\mathrm{SCD}_{\text {ref }}$ and $\alpha$. Temperature and pressure as measured on the plane were used to prescribe the vertical distribution of $\mathrm{O}_{4}$ in the model. Temperature and pressure 


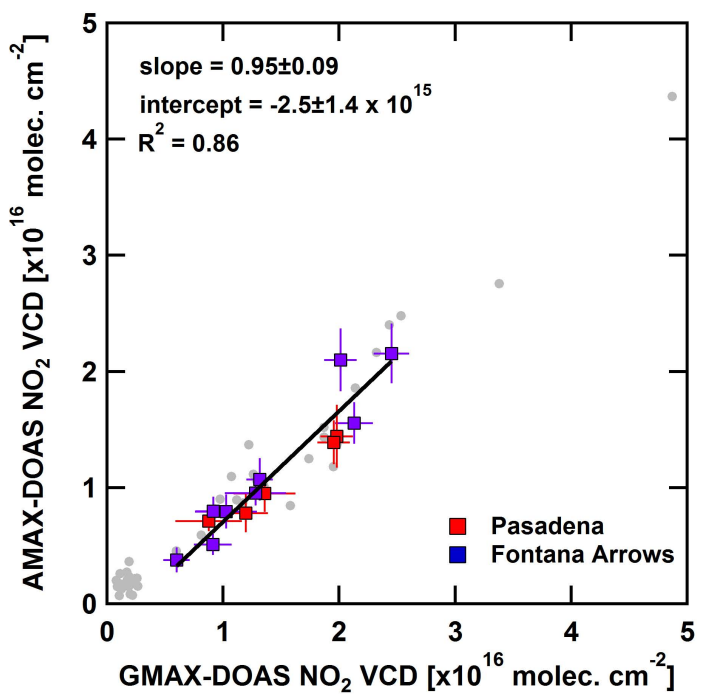

Fig. 8. Correlation plot of $\mathrm{NO}_{2}$ VCDs between CU AMAX-DOAS and two MAX-DOAS instruments deployed in California during the CalNex and CARES field campaigns. Grey dots represent all data from both CalNex and CARES campaigns (see text for filtering conditions). Data from CalNex further constrained for relative azimuth between plane heading and MAX-DOAS viewing geometry $< \pm 15^{\circ}$ and $\mathrm{NO}_{2}$ VCD variability $<8 \mathrm{x} \times 10^{15}$ molecules $\mathrm{cm}^{-2}$ are shown in red and blue. Black line is the linear fit through the colored points.

profiles were extrapolated to the ground using the lapse rate and scale height determined from the measurements, respectively. The temperature was $36.7^{\circ} \mathrm{C}$ and the pressure was 966 mbar at the ground. Comparison of extrapolated temperature and pressure values at the ground with measurements at the nearest CARB monitoring stations showed good agreement within $\pm 2{ }^{\circ} \mathrm{C}$ and \pm 10 mbar, respectively. Profiles above the aircraft were extrapolated based on the mean temperature and pressure profiles measured at Joshua Tree, CA. The $\mathrm{O}_{3}$ profile was also constructed similarly and was measured by the NOAA TOPAZ lidar aboard the plane. Based on the regression analysis shown in Fig. 9, between simulated and measured $\mathrm{O}_{4} \mathrm{SCDs}$ at $477 \mathrm{~nm}$ for the low approach at Brackett airfield during RF\#46 (see more details below), we determine $\alpha=0.99 \pm 0.01$ for $477 \mathrm{~nm}$. Hence, it is concluded that a scaling factor is not needed to explain our measurements. An $\mathrm{O}_{4}$ reference SCD of $9 \times 10^{42}$ molecule $^{2} \mathrm{~cm}^{-5}$ based on the regression has been added to the measured dSCDs to convert them to SCDs.

\subsubsection{Aerosol extinction coefficient profiles}

The aerosol extinction coefficient vertical distribution retrieved at $477 \mathrm{~nm}$ is shown in Fig. 10b. The extinction profile was retrieved by iteratively minimizing the residual between measured and simulated $\mathrm{O}_{4}$ SCDs; see Sect. 3.4. Figure 10a illustrates the agreement between the measured and modeled

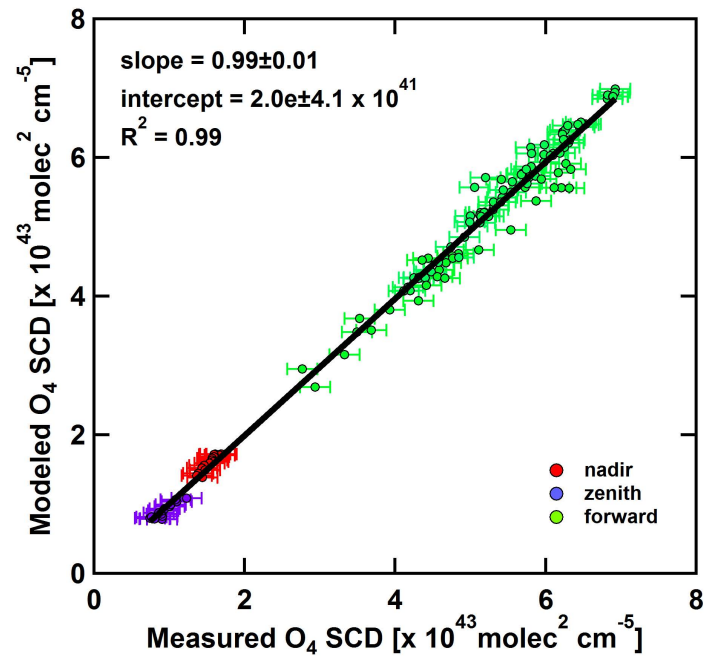

Fig. 9. Correlation plot of modeled and measured $\mathrm{O}_{4} \mathrm{SCDs}$ at $477 \mathrm{~nm}$ for the case study shown in Fig. 10b. SCD of the zenith reference $\left(9 \times 10^{42}\right.$ molecules $\left.{ }^{2} \mathrm{~cm}^{-5}\right)$ has been added to the measured $\mathrm{O}_{4}$ dSCDs. Forward viewing geometry includes $0^{\circ}, \pm 2^{\circ}, \pm 5^{\circ}$ EAs.

$\mathrm{O}_{4} \mathrm{SCDs}$ at $477 \mathrm{~nm}$ for $0^{\circ} \mathrm{EA}$. The corresponding aerosol extinction profile is presented in Fig. 10b. The aerosol extinction profile in Fig. 10b indicates that most of the aerosols are located inside the BL (up to $0.9 \mathrm{~km}$, indicated by the decrease in $\mathrm{NO}_{2}$ and aerosol) with a 500-m-thick elevated layer at $\sim 2.5 \mathrm{~km}$. The error contribution in retrieved extinction due to EA uncertainty of $0.35^{\circ}$ is shown in Fig. 10c, and it illustrates that pointing accuracy is needed especially to minimize error in transition layers and elevated layers.

Integration of the extinction coefficient profile over altitude gives AOD - the total load of aerosols in the atmosphere. AOD at $477 \mathrm{~nm}$ from the profile in Fig. 10b is $0.16 \pm 0.03$ and agrees well with $0.18 \pm 0.02$ at $500 \mathrm{~nm}$ measured by the AERONET station located at Pasadena. The AOD values for the AERONET station reported here are hourly averages and standard deviations for the hour of the low approach. Pasadena is located $30 \mathrm{~km}$ west of the Brackett airfield; the telescope was pointing towards the west during our low approach, and measurements inherently average over spatial scales of typically few $10 \mathrm{~km}$. Based on the Koschmieder visibility formula for the visible wavelength region - visibility $=3.91$ /extinction coefficient (see e.g., Horvath, 1971) - the visibility at $477 \mathrm{~nm}$ during the time of our measurement would be $\sim 39 \mathrm{~km}$. The excellent agreement between the AOD calculated from our profiles and AERONET station adds confidence to our retrieval approach and accuracy of the retrieved profile. To our knowledge this is the first demonstration of quantitative retrieval of aerosol extinction from $\mathrm{O}_{4} \mathrm{dSCD}$ observations that does not require a correction factor. 

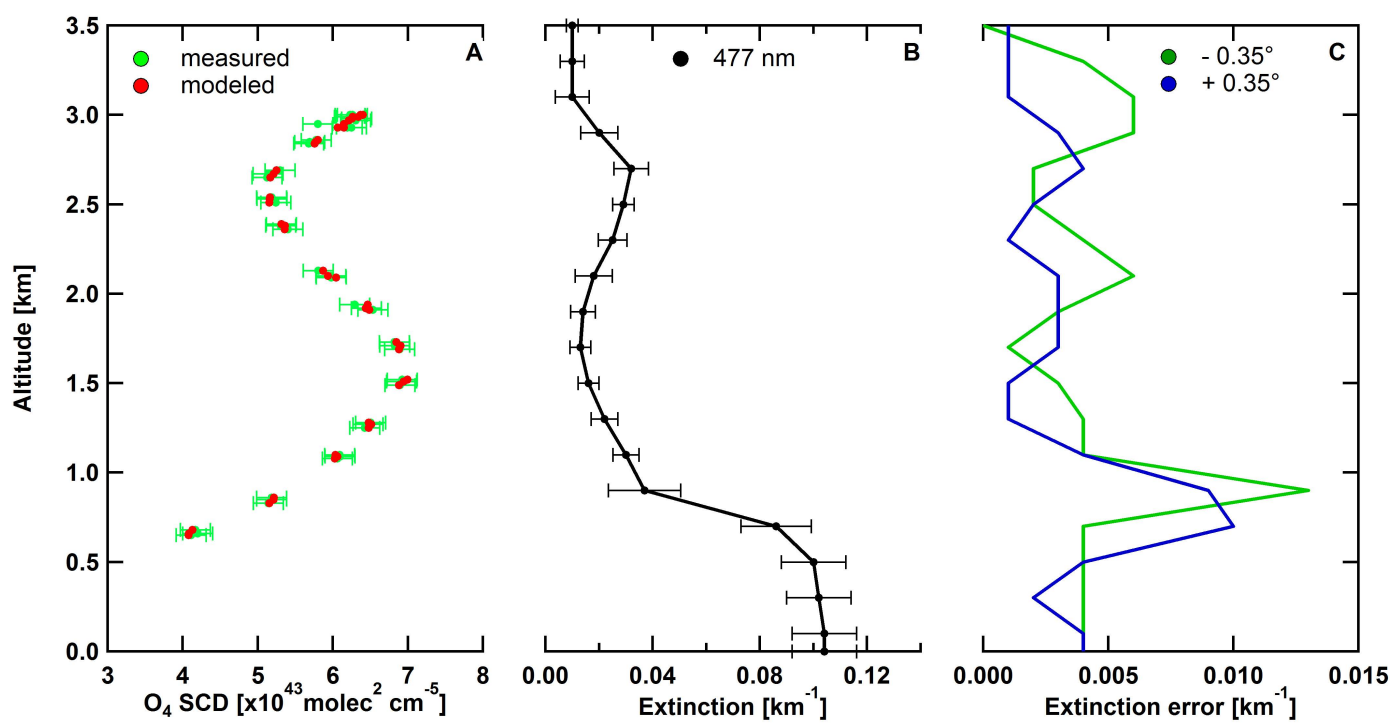

Fig. 10. (A) Measured (green) and simulated (red) vertical profiles of $\mathrm{O}_{4} \mathrm{SCDs}$ for $0^{\circ} \mathrm{EA}$ at $477 \mathrm{~nm}$ from the low approach at Brackett airfield during RF\#46 on 16 July 2010 in SCAB. (B) Corresponding aerosol extinction vertical profile retrieved at $477 \mathrm{~nm}$. (C) Error contribution in extinction due to angle uncertainty of $\pm 0.35^{\circ}$. Note that the aircraft only flew down to $\sim 600 \mathrm{~m}$ a.g.l. during the low approach, and a set of downward EAs at that altitude was used to probe the lower altitudes.

\subsubsection{Trace gas vertical profiles}

Figure 11 shows the retrieved $\mathrm{NO}_{2}, \mathrm{CHOCHO}, \mathrm{HCHO}$ and $\mathrm{H}_{2} \mathrm{O}$ mixing ratio profiles from the same low approach. The $\mathrm{NO}_{2}, \mathrm{CHOCHO}$, and $\mathrm{HCHO}$ vertical profiles have a very similar shape, with most of the trace gases located inside the BL. This is not surprising since most of the sources for these gases are close to the surface. On the other hand, the $\mathrm{H}_{2} \mathrm{O}$ profile is almost linearly decreasing with altitude. The retrieved $\mathrm{NO}_{2}$ profile shows an average urban $\mathrm{BL}$ value of $14.2 \pm 1.3 \mathrm{ppb}$ (at the surface: $1 \mathrm{ppb} \cong 2.46 \times 10^{10}$ molecules $\mathrm{cm}^{-3}$ at sea level, and $298 \mathrm{~K}$ temperature). The hourly $\mathrm{NO}_{2}$ data recorded at the nearest CARB monitoring station at Pomona, CA are $13 \mathrm{ppb}$. Pomona station is located $\sim 3 \mathrm{~km}$ south of the Brackett airfield. Our retrieved $\mathrm{NO}_{2}$ surface mixing ratio agrees well with the measurement at the ground station. The $\mathrm{CHOCHO}$ profile shows a BL value of $274 \pm 28$ ppt. It also exhibits an elevated layer of $\mathrm{CHOCHO}$ with $\sim 33 \pm 8 \mathrm{ppt}$ at around $2.5 \mathrm{~km}$ (Fig. 11b). The lower error bars in the FT compared to the BL is due to two reasons: (1) with both the reference spectrum and the measured spectrum taken under very similar conditions, i.e., FT with lower aerosol load compared to $\mathrm{BL}$, the DOAS retrieval error is smaller in the FT compared to BL. (2) In our low approach, the aircraft only descended down to an altitude of $\sim 600 \mathrm{~m}$ a.g.l. , and a set of downward EAs at that altitude was used to probe the lower altitudes. Hence, the measurement has relatively lower sensitivity below $600 \mathrm{~m}$ (see Fig. S1 in the Supplement). The observation of 33 ppt CHOCHO in a layer aloft that is decoupled from the boundary layer coincides with the altitude where a layer of enhanced aerosol is observed in the aerosol extinction profile (Fig. 10b). The coexistence of $\mathrm{CHOCHO}$ and aerosol aloft could indicate the in situ production of $\mathrm{CHO}$ $\mathrm{CHO}$ from oxidation of VOCs that have been transported along with the aerosols. Laboratory studies show consistent evidence of CHOCHO uptake by aerosols forms SOA (Liggio et al., 2005; Volkamer et al., 2009b; Trainic et al., 2011). However, if this process is partly reversible, the collocation of $\mathrm{CHOCHO}$ and aerosol could also point to aerosols as a source of CHOCHO aloft (Kroll et al., 2005; Kampf et al., 2013). It should be noted that while CHOCHO dSCDs at the elevated layers are close to the detection limit for our $2 \mathrm{~s}$ data, this detection limit can be improved by longer averaging times. An elevated layer of $\mathrm{O}_{3}$ is also observed in the NOAA TOPAZ lidar data at the same altitude (C. Senff, CIRES \& NOAA, personal communication, 2012) and is included in the RTM calculations for aerosol extinction and trace gas inversion. The water vapor mixing ratio inside the $\mathrm{BL}$ corresponds to a relative humidity, $\mathrm{RH}=23 \pm 5 \%$. Coincident measurements of RH at nearby CARB monitoring stations varied from $\mathrm{RH}=23 \%$ (Ontario International Airport) to $\mathrm{RH}=34 \%$ (Upland, CA). The good agreement of $\mathrm{RH}$ demonstrates control of radiation fields in the inversion. $\mathrm{HCHO}$ vertical profile was retrieved using aerosol extinction profile independently obtained using $\mathrm{O}_{4}$ dSCD measurements at $360 \mathrm{~nm}$ (see Fig. S2 in the Supplement).

A $250 \mathrm{~m}$ altitude grid was chosen for the retrieval of trace gases. This grid height was chosen based on the FOV of the telescope, rate of aircraft descent and time it took to complete one EA scan cycle during the descent. The averaging kernels for all the trace gases indicate a constant sensitivity 

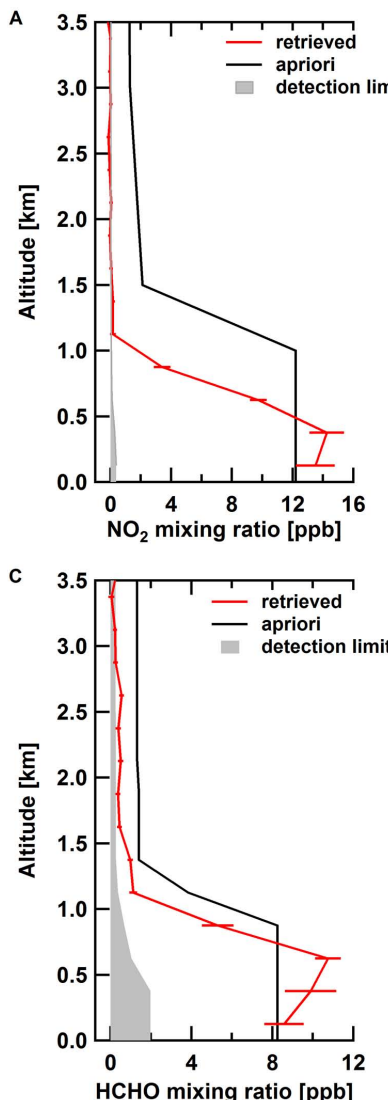
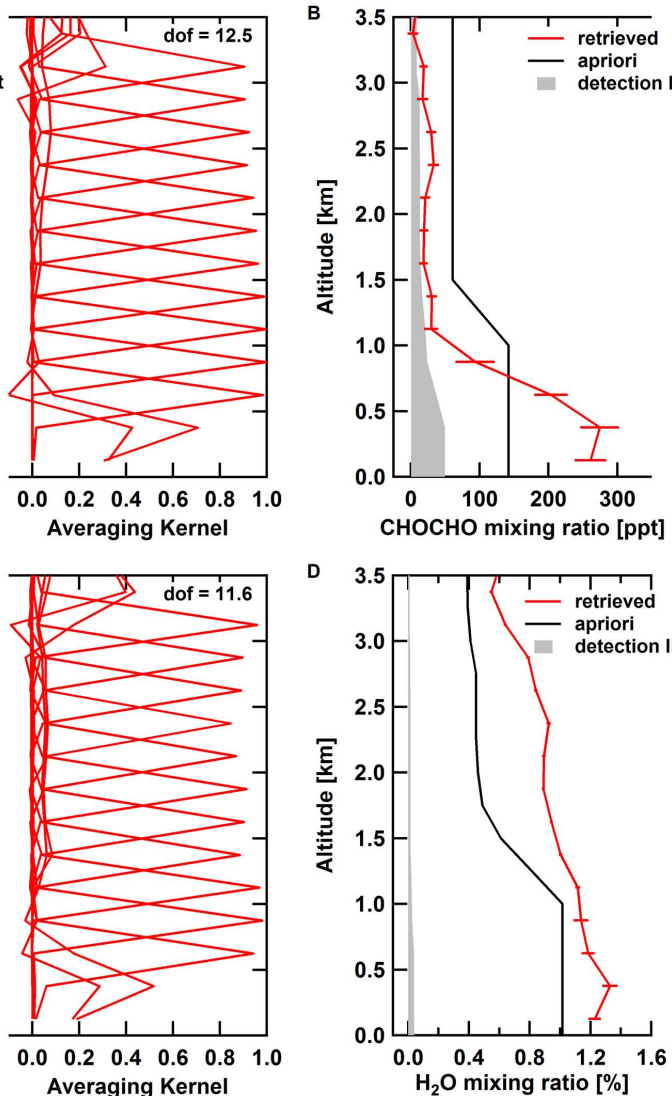

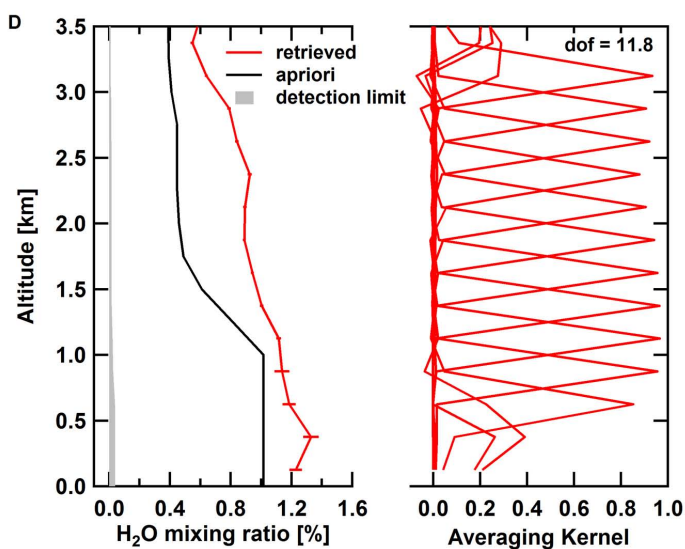

Fig. 11. Retrieved vertical profiles and corresponding averaging kernels for (A) $\mathrm{NO}_{2}$, (B) $\mathrm{CHOCHO}$, (C) $\mathrm{HCHO}$ and $(\mathbf{D}) \mathrm{H}_{2} \mathrm{O}$ from the low approach at Brackett airfield. $\mathrm{NO}_{2}, \mathrm{CHOCHO}$ and $\mathrm{HCHO}$ profiles show most of the trace gases are located close to the source region inside the BL. Averaging kernels indicate almost constant sensitivity for all trace gases over the entire altitude range. Grey shaded area represents detection limit for each profile.

for the whole low approach except the lowest layer at the surface. The DOF are 12.5, 11.5, 11.6, and 11.8 for $\mathrm{NO}_{2}, \mathrm{CHO}$ $\mathrm{CHO}, \mathrm{HCHO}$, and $\mathrm{H}_{2} \mathrm{O}$, respectively confirming the presence of independent information approximately every $250 \mathrm{~m}$. The sensitivity of the retrieved profile to different a priori profiles was also tested, and the lowest layer inside the BL was found to be the most susceptible (up to $20 \%$ ), which is the layer with the least measurement sensitivity. The lower averaging kernels below $600 \mathrm{~m}$ are explained from the observing geometry of the low approach (see above). While this decrease in sensitivity for other EAs compared to $0^{\circ}$ for a given atmospheric layer does not appear to limit our ability to infer meaningful information near the surface (see this section above), it highlights the benefit of capabilities to maintain $0^{\circ}$ EA during aircraft ascent/descent to systematically probe the atmosphere with maximum sensitivity and vertical resolution.

The averaging kernels (Fig. 11) appear as if there were no other EAs but $0^{\circ}$ EA used for the profile retrievals. In fact, they peak at the altitude of $0^{\circ}$ EA measurements. This highlights the fact that $0^{\circ} \mathrm{EA}$ is the most sensitive EA during ascent and descent of the aircraft and provides the most independent information. This has also been reported by Merlaud et al. (2011). Bruns et al. (2004) performed theoretical sensitivity study regarding choice of EA for maximizing DOF while flying at a constant altitude. Based on the study by Bruns et al. (2004) and our experiment, we recommend maintaining $0^{\circ}$ EA actively aligned during descent/ascent and scanning only at the lowest and highest point during the ascent/descent to maximize DOF.

\section{Conclusions}

An airborne MAX-DOAS instrument equipped with a motion-stabilized scanning telescope to collect solar stray light photons provides accurate means to probe atmospheric composition in terms of the horizontal and vertical distributions of multiple trace gases and aerosols simultaneously and sensitively by means of a single, portable instrument.

The CU AMAX-DOAS instrument is validated by comparison with $\mathrm{NO}_{2}$ VCDs measured by ground-based MAXDOAS. A sensitivity study using radiative transfer modeling 
reveals that the geometric approximation is a viable option to convert $\mathrm{NO}_{2} \mathrm{SCD}$ to $\mathrm{VCD}$ for measurements below the plane. This approximation is found to be accurate over southern California, where elevated SA $(\sim 10 \%$ at $477 \mathrm{~nm}$ wavelength, measured aboard the plane) compensates for reduced sensitivity due to aerosols. We estimate the error in the $\mathrm{NO}_{2}$ vertical columns due to the geometric approximation to be less than $7 \%$ under most conditions for $\mathrm{SZA}<65^{\circ}$; a slightly larger error $(<25 \%$ in all cases $)$ is found for SZA $\sim 65^{\circ}$ or during high-altitude flights over low SA. These results emphasize benefits of measuring SA and AOD by independent sensors.

For a case study, vertical profiles of $\mathrm{NO}_{2}, \mathrm{CHOCHO}$, $\mathrm{HCHO}, \mathrm{H}_{2} \mathrm{O}$, and aerosol extinction coefficient at $477 \mathrm{~nm}$ showed that trace gases and aerosols are located mostly inside the BL, though the presence of an elevated pollution layer was observed as well. Sensitivity studies show that the main error sources in the retrieved vertical profiles of aerosol extinction are due to the asymmetry parameter of aerosol scattering. Further, sensitivity studies highlight the need of pointing accuracy of the telescope on moving platforms like an aircraft to accurately retrieve vertical distributions of trace gases and aerosol extinction coefficients. The accuracy of our motion compensation is found to be $<0.35^{\circ}$ by comparison with an independent inertia system.

An $\sim 500$-m-thick layer at around $2.5 \mathrm{~km}$ altitude a.g.l. was observed that was decoupled from the $\mathrm{BL}$, and contained $33 \pm 8$ ppt $\mathrm{CHOCHO}, \mathrm{NO}_{2}$ below the detection limit (30 ppt, for $2 \mathrm{~s}$ integration time), $545 \pm 114 \mathrm{ppt} \mathrm{HCHO}$, $0.029 \pm 0.004 \mathrm{~km}^{-1} \varepsilon_{477}$, corresponding to a partial vertical columns of $4.14 \pm 1.12 \times 10^{13}$ molecules $\mathrm{cm}^{-2} \mathrm{CHO}$ $\mathrm{CHO}, 7.10 \pm 1.75 \times 10^{14}$ molecules $\mathrm{cm}^{-2} \mathrm{HCHO}$, and partial AOD of $0.047 \pm 0.007$ at $477 \mathrm{~nm}$. This elevated layer contained ratios of $\mathrm{CHOCHO} / \mathrm{HCHO}$ of $0.06 \pm 0.02$, compared to $0.027 \pm 0.006$ inside the BL. The concurrent location of elevated aerosol extinction at the same altitude indicates either collocated CHOCHO sources from VOC oxidation, or the release of $\mathrm{CHOCHO}$ that was initially taken up as SOA back to the gas phase. The increase in the CHO$\mathrm{CHO} / \mathrm{HCHO}$ ratio with altitude appears to be outside error bars, and the cause for this altitude dependence deserves further investigation.

The capabilities of CU AMAX-DOAS are not limited to the parameters presented here, and also include measurements of reactive species such as halogen oxide radicals (e.g., Dix et al., 2013), and aerosols at other wavelengths. The absence of sampling lines, and inherent averaging over extended spatial scales enable the AMAX-DOAS technique to bridge between ground-based networks, atmospheric models, and satellites, and holds as yet unexplored potential to advance airborne atmospheric observations, and improve our understanding of the processes taking place in the atmosphere. The CU AMAX-DOAS deployment during the CalNex and CARES field campaigns makes a 10-weeklong data set available that we plan to apply for such studies.
Appendix A

Table A1. List of frequently used abbreviations.

\begin{tabular}{ll}
\hline a.g.l. & above ground level \\
AMAX-DOAS & $\begin{array}{l}\text { airborne multi-axis differential optical } \\
\text { absorption spectroscopy }\end{array}$ \\
AMF & air mass factor \\
AOD & aerosol optical depth \\
BL & boundary layer \\
BLH & boundary layer height \\
CalNex & California Research at the Nexus of \\
& Air Quality and Climate Change \\
CARB & California Air Resources Board \\
CARES & Carbonaceous Aerosols and Radiative \\
EAMF & Effects Study \\
differential air mass factor \\
differential slant column density \\
DOF & degrees of freedom \\
EA & elevation angle \\
FOV & field of view \\
FT & free troposphere \\
FWHM & full width at half maximum \\
geoAMF & geometric air mass factor \\
LOS & lines of sight \\
MAX-DOAS & multi-axis differential optical absorption \\
spectroscopy \\
RF
\end{tabular}

Supplementary material related to this article is available online at: http://www.atmos-meas-tech.net/6/ 719/2013/amt-6-719-2013-supplement.pdf. 
Acknowledgements. This work was supported by the California Air Resource Board (CARB) contract 09-317, the National Science Foundation CAREER award ATM-847793, CU startup funds (RV) and an ESRL-CIRES Graduate Fellowship (SB). The authors thank Dr. Jochen Stutz for providing AERONET data at the Caltech site. The authors like to thank Tim Deutschmann, University of Heidelberg for the radiative transfer code, McArtim, David Thomson for the software support, Caroline Fayt and Michel van Roozendael for the WinDOAS software and the NOAA Twin Otter research flight crew.

\section{Edited by: J. Stutz}

\section{References}

Alvarez II, R. J., Senff, C. J., Langford, A. O., Weickmann, A. M., Law, D. C., Machol, J. L., Merritt, D. A., Marchbanks, R. D., Sandberg, S. P., Brewer, W. A., Hardesty, R. M., and Banta, R. M.: Development and Application of a Compact, Tunable, Solid-State Airborne Ozone Lidar System for Boundary Layer Profiling, J. Atmos. Ocean. Tech., 28, 1258-1272, doi:10.1175/JTECH-D-10-05044.1, 2011.

Barret, B., De Maziere, M., and Demoulin, P.: Retrieval and characterization of ozone profiles from solar infrared spectra at the Jungfraujoch, J. Geophys. Res.-Atmos., 107, 4788, doi:10.1029/2001JD001298, 2002.

Blickendsdorfer, R. P. and Ewing, G. E.: Collision-Induced Absorption Spectrum of Gaseous Oxygen at Low Temperatures and Pressures, II. The Simultaneous Transitions ${ }^{1} \Delta_{g}+{ }^{1} \Delta_{g}<-$ ${ }^{3} \sum_{g}+{ }^{3} \sum_{g}$ and ${ }^{1} \Delta_{g}+{ }^{1} \sum_{g}+<-{ }^{3} \sum_{g}+{ }^{3} \sum_{g}$, J. Chem. Phys., 51, 5284-5289, doi:10.1063/1.1671946, 1969.

Bogumil, K., Orphal, J., Homann, T., Voigt, S., Spietz, P., Fleischmann, O., Vogel, A., Hartmann, M., Kromminga, H., Bovensmann, H., Frerick, J., and Burrows, J.: Measurements of molecular absorption spectra with the SCIAMACHY pre-flight model: instrument characterization and reference data for atmospheric remote-sensing in the $230-2380 \mathrm{~nm}$ region, J. Photoch. Photobio. A, 157, 167-184, doi:10.1016/S1010-6030(03)00062-5, 2003.

Bruns, M., Buehler, S. A., Burrows, J. P., Heue, K. P., Platt, U., Pundt, I., Richter, A., Rozanov, A., Wagner, T., and Wang, P.: Retrieval of Pro?le Information from Airborne Multi AxisUV/visible Skylight Absorption Measurements, Appl. Optics, 43, 4415-4426, doi:10.1364/AO.43.004415, 2004.

Bruns, M., Buehler, S. A., Burrows, J. P., Richter, A., Rozanov, A., Wang, P., Heue, K. P., Platt, U., Pundt, I., and Wagner, T.: $\mathrm{NO}_{2}$ Profile retrieval using airborne multi axis UV-visible skylight absorption measurements over central Europe, Atmos. Chem. Phys., 6, 3049-3058, doi:10.5194/acp-6-3049-2006, 2006.

Bussemer, M.: Der Ring-Effekt: Ursachen und Einfluß auf die spektroskopische Messung stratosphärischer Spurenstoffe, Diploma Thesis thesis/masters, University of Heidelberg, Heidelberg, Germany, 1993.

Chance, K. and Orphal, J.: Revised ultraviolet absroption cross sections of $\mathrm{H}_{2} \mathrm{CO}$ for the HITRAN database, J. Quant. Spectrosc. Ra., 112, 1509-1510, doi:10.1016/j.jqsrt.2011.02.002, 2011.
Clémer, K., Van Roozendael, M., Fayt, C., Hendrick, F., Hermans, C., Pinardi, G., Spurr, R., Wang, P., and De Mazière, M.: Multiple wavelength retrieval of tropospheric aerosol optical properties from MAXDOAS measurements in Beijing, Atmos. Meas. Tech., 3, 863-878, doi:10.5194/amt-3-863-2010, 2010.

Coburn, S., Dix, B., Sinreich, R., and Volkamer, R.: The CU ground MAX-DOAS instrument: characterization of RMS noise limitations and first measurements near Pensacola, FL of BrO, IO, and CHOCHO, Atmos. Meas. Tech., 4, 2421-2439, doi:10.5194/amt-4-2421-2011, 2011.

Deutschmann, T., Beirle, S., Friess, U., Grzegorski, M., Kern, C., Kritten, L., Platt, U., Prados-Roman, C., Pukite, J., Wagner, T., Werner, B., and Pfeilsticker, K.: The Monte Carlo atmospheric radiative transfer model McArtim: Introduction and validation of Jacobians and 3D features, J. Quant. Spectrosc. Ra., 112, 11191137, doi:10.1016/j.jqsrt.2010.12.009, 2011.

Dix, B., Brenninkmeijer, C. A. M., Frieß, U., Wagner, T., and Platt, U.: Airborne multi-axis DOAS measurements of atmospheric trace gases on CARIBIC long-distance flights, Atmos. Meas. Tech., 2, 639-652, doi:10.5194/amt-2-639-2009, 2009.

Dix, B., Baidar, S., Bresch, J. F., Hall, S. R., Schmidt, K. S., Wang, S., and Volkamer, R.: Detection of Iodine Monoxide in the Tropical Free Troposphere, Proc. Natl. Acad. Sci., 110, 2035-2040, doi:10.1073/pnas.1212386110, 2013.

Dubovik, O., Holben, B., Eck, T. F., Smirnov, A., Kaufman, Y. F., King, M. D., Tanré, D., and Slutsker, I.: Variability of absorption and optical properties of key aerosol types observed in worldwide locations, J. Atmos. Sci., 59, 590-608, doi:10.1175/15200469(2002)059<0590:VOAAOP>2.0.CO;2, 2002.

Fayt, C. and Van Roozendael, M.: WinDOAS 2.1, Software User Manual, available at: http://bro.aeronomie.be/ WinDOAS-SUM-201b.pdf, last access: 29 May 2012, Belgian Institute for Space Aeronomy, Brussels, Belgium, 2001.

Grainger, J. and Ring, J.: Anomalous Fraunhofer Line Profiles, Nature, 193, p. 762, doi:10.1038/193762a0, 1962.

Greenblatt, G. D., Orlando, J. J., Burkholder, J. B., and Ravishankara, A. R.: Absorption-Measurements of Oxygen between $330 \mathrm{~nm}$ and $1140 \mathrm{~nm}$, J. Geophys. Res., 95, 18577-18582, doi:10.1029/JD095iD11p18577, 1990.

Griffin, R. J., Revelle, M. K., and Dabdub, D.: Modeling the oxidative capacity of the atmosphere of the south coast air basin of California, 1. Ozone formation metrics, Environ. Sci. Technol., 38, 746-752, doi:10.1021/es0341283, 2004.

Hendrick, F., Barret, B., Van Roozendael, M., Boesch, H., Butz, A., De Mazière, M., Goutail, F., Hermans, C., Lambert, J.C., Pfeilsticker, K., and Pommereau, J.-P.: Retrieval of nitrogen dioxide stratospheric profiles from ground-based zenithsky UV-visible observations: validation of the technique through correlative comparisons, Atmos. Chem. Phys., 4, 2091-2106, doi:10.5194/acp-4-2091-2004, 2004.

Hendrick, F., Van Roozendael, M., Kylling, A., Petritoli, A., Rozanov, A., Sanghavi, S., Schofield, R., von Friedeburg, C., Wagner, T., Wittrock, F., Fonteyn, D., and De Mazière, M.: Intercomparison exercise between different radiative transfer models used for the interpretation of ground-based zenith-sky and multi-axis DOAS observations, Atmos. Chem. Phys., 6, 93-108, doi:10.5194/acp-6-93-2006, 2006. 
Hermans, C.: Measurement of absorption cross sections and spectroscopicmolecular parameters: $\mathrm{O}_{2}$ and its collisional induced absorption, available at: http://spectrolab.aeronomie.be/o2.htm (last access: 29 May 2012), 2002.

Heue, K.-P., Richter, A., Bruns, M., Burrows, J. P., v. Friedeburg, C., Platt, U., Pundt, I., Wang, P., and Wagner, T.: Validation of SCIAMACHY tropospheric $\mathrm{NO}_{2}$-columns with AMAXDOAS measurements, Atmos. Chem. Phys., 5, 1039-1051, doi:10.5194/acp5-1039-2005, 2005.

Hönninger, G., von Friedeburg, C., and Platt, U.: Multi axis differential optical absorption spectroscopy (MAX-DOAS), Atmos. Chem. Phys., 4, 231-254, doi:10.5194/acp-4-231-2004, 2004.

Horvath, H.: Applicability of Koschmieder Visibility Formula, Atmos. Environ., 5, 177-184, doi:10.1016/0004-6981(71)90081-3, 1971.

Kampf, C. J., Waxman, E. M., Slowik, J. G., Dommen, J., Pfaffenberger, L., Praplan, A., Prevot, A., Baltensperger, U., Hoffmann, T., and Volkamer, R.: Direct effective Henry's law constant measurements for glyoxal in model aerosols containing sulfate, Environ. Sci. Technol., submitted, 2013.

Kritten, L., Butz, A., Dorf, M., Deutschmann, T., Kühl, S., PradosRoman, C., Pukite, J., Rozanov, A., Schofield, R., and Pfeilsticker, K.: Time dependent profile retrieval of UV/vis absorbing radicals from balloon-borne limb measurements - a case study on $\mathrm{NO}_{2}$ and $\mathrm{O}_{3}$, Atmos. Meas. Tech., 3, 933-946, doi:10.5194/amt3-933-2010, 2010.

Kroll, J. H., Ng, N. L., Murphy, S. M., Varutbangkul, V., Flagan, R. C., and Seinfeld, J. H.: Chamber studies of secondary organic aerosol growth by reactive uptake of simple carbonyl compounds, J. Geophys. Res.-Atmos., 110, D23207, doi:10.1029/2005JD006004, 2005.

Liggio, J., Li, S., and McLaren, R.: Reactive uptake of glyoxal by particulate matter, J. Geophys. Res., 110, D10304, doi:10.1029/2004JD005113, 2005.

McElroy, C. T.: Stratospheric Nitrogen-Dioxide Concentrations as Determined from Limb Brightness Measurements made on June 17, 1983, J. Geophys. Res.-Atmos., 93, 7075-7083, doi:10.1029/JD093iD06p07075, 1988.

Melamed, M. L., Solomon, S., Daniel, J. S., Langford, A. O., Portmann, R. W., Ryerson, T. B., Nicks, D. K. J., and and McKeen, S. A.: Measuring reactive nitrogen emissions from pointsources using visible spectroscopy from aircraft, J. Environ. Monit., 5, 29-34, doi:10.1039/B204220G, 2003.

Melamed, M. L., Langford, A. O., Daniel, J. S., Portmann, R. W., Miller, H. L., Eubank, C. S., Schofield, R., Holloway, J., and Solomon, S.: Sulfur dioxide emission flux measurements from point sources using airborne near ultraviolet spectroscopy during the New England Air Quality Study 2004, J. Geophys. Res., 113, D02305, doi:10.1029/2007JD008923, 2008.

Meller, R. and Moortgat, G.: Temperature dependence of the absorption cross sections of formaldehyde between 223 and $323 \mathrm{~K}$ in the wavelength range $225-375 \mathrm{~nm}$, J. Geophys. Res., 105, 7089-7101, doi:10.1029/1999JD901074, 2000.

Merlaud, A., Van Roozendael, M., Theys, N., Fayt, C., Hermans, C., Quennehen, B., Schwarzenboeck, A., Ancellet, G., Pommier, M., Pelon, J., Burkhart, J., Stohl, A., and De Mazière, M.: Airborne DOAS measurements in Arctic: vertical distributions of aerosol extinction coefficient and $\mathrm{NO}_{2}$ concentration, Atmos. Chem. Phys., 11, 9219-9236, doi:10.5194/acp-11-9219-2011, 2011.
Oetjen, H., Baidar, S., Krotkov, N. A., Lamsal, L. N., and Volkamer, R.: Testing the NASA OMI tropospheric $\mathrm{NO}_{2}$ product over California for summer 2010 using airborne MAX-DOAS measurements, J. Geophys. Res.-Atmos., submitted, 2013.

Ortega, I., Baidar, S., Coburn, S., Dix, B., Oetjen, H., Sinreich, R., and Volkamer, R.: Comparison of regularization and optimal estimation inversion techniques to retrieve trace gas profiles from ground-based MAX-DOAS, in preparation, 2013.

Pearson, G., Davies, F., and Collier, C.: An Analysis of the Performance of the UFAM Pulsed Doppler Lidar for Observing the Boundary Layer, J. Atmos. Ocean. Tech., 26, 240-250, doi:10.1175/2008JTECHA1128.1, 2009.

Petritoli, A., Ravegnani, F., Giovanelli, G., Bortoli, D., Bonafe, U., Kostadinov, I., and Oulanovsky, A.: Off-axis measurements of atmospheric trace gases by use of an airborne ultraviolet-visible spectrometer, Appl. Optics, 41, 5593-5599, doi:10.1364/AO.41.005593, 2002.

Platt, U. and Stutz, J.: Differential Optical Absorption Spectroscopy: Principles and Applications, Springer Verlag, Heidelberg, 2008.

Pope III, C. A., Ezzati, M., and Dockery, D. W.: Fine-Particulate Air Pollution and Life Expectancy in the United States, N. Engl. J. Med., 360, 376-386, doi:10.1056/NEJMsa0805646, 2009.

Prados-Roman, C., Butz, A., Deutschmann, T., Dorf, M., Kritten, L., Minikin, A., Platt, U., Schlager, H., Sihler, H., Theys, N., Van Roozendael, M., Wagner, T., and Pfeilsticker, K.: Airborne DOAS limb measurements of tropospheric trace gas profiles: case studies on the profile retrieval of $\mathrm{O}_{4}$ and $\mathrm{BrO}$, Atmos. Meas. Tech., 4, 1241-1260, doi:10.5194/amt-4-1241-2011, 2011.

Rodgers, C. D.: Inverse Methods for Atmospheric Sounding: Theory and Practice, World Scientific, Singapore, 2000.

Roscoe, H. K. and Hill, J. G. T.: Vertical resolution of oversampled limb-sounding measurements from satellites and aircraft, J. Quant. Spectrosc. Ra., 72, 237-248, doi:10.1016/S00224073(01)00121-2, 2002.

Rothman, L., Jacquemart, D., Barbe, A., Benner, D., Birk, M., Brown, L., Carleer, M., Chackerian, C., Chance, K., Coudert, L., Dana, V., Devi, V., Flaud, J., Gamache, R., Goldman, A., Hartmann, J., Jucks, K., Maki, A., Mandin, J., Massie, S., Orphal, J., Perrin, A., Rinsland, C., Smith, M., Tennyson, J., Tolchenov, R., Toth, R., Vander Auwera, J., Varanasi, P., and Wagner, G.: The HITRAN 2004 molecular spectroscopic database, J. Quant. Spectrosc. Ra., 96, 139-204, doi:10.1016/j.jqsrt.2004.10.008, 2005.

Ryerson, T. B., Andrews, A. E., Angevine, W. M., Bates, T. S., Brock, C. A., Cohen, R. C., Cooper, O. R., de Gouw, J. A., Fehsenfeld, F. C., Ferrare, R. A., Fischer, M. L., Flagan, R. C., Goldstein, A. H., Hair, J. W., Hardesty, R. M., Hostetler, C. A., Jimenez, J. L., Langford, A. O., McCauley, E., McKeen, S. A., Molina, L. T., Nenes, A., Oltmans, S. J., Parrish, D. D., Pederson, J. R., Pierce, R. B., Prather, K., Quinn, P. K., Seinfeld, J. H., Senff, C., Sorooshian, A., Stutz, J., Surratt, J. D., Trainer, M., Volkmer, R., Williams, E. J., and Wofsy, S. C.: The 2010 California Research at the Nexus of Air Quality and Climate Change (CalNex) field study, J. Geophys. Res.-Atmos., submitted, 2013. 
Schiller, C., Wahner, A., Platt, U., Dorn, H. P., Callies, J., and Ehhalt, D. H.: Near Uv Atmospheric Absorption-Measurements of Column Abundances during Airborne Arctic Stratospheric Expedition, January-February 1989, 2. Oclo Observations, Geophys. Res. Lett., 17, 501-504, doi:10.1029/GL017i004p00501, 1990.

Schofield, R., Connor, B. J., Kreher, K., Johnston, P. V., and Rodgers, C. D.: The retrieval of profile and chemical information from ground-based UV-visible spectroscopic measurements, J. Quant. Spectrosc. Ra., 86, 115-131, doi:10.1016/s00224073(03)00278-4, 2004.

Sinreich, R., Coburn, S., Dix, B., and Volkamer, R.: Ship-based detection of glyoxal over the remote tropical Pacific Ocean, Atmos. Chem. Phys., 10, 11359-11371, doi:10.5194/acp-1011359-2010, 2010.

Thalman, R. and Volkamer, R.: Temperature Dependent Absorption Cross-Sections of $\mathrm{O}_{2}-\mathrm{O}_{2}$ collision pairs between 340 and $630 \mathrm{~nm}$ at atmospheric pressure, submitted, 2013.

Thomson, J., Hayes, P. L., Jimenez, J. L., Adachi, K., Zhang, X., Liu, J., Weber, R. J., and Buseck, R. R.: Aerosol Optical Properties at Pasadena, CA During CalNex 2010, Atmos. Environ., 55, 190-200, doi:10.1016/j.atmosenv.2012.03.011, 2012.

Trainic, M., Abo Riziq, A., Lavi, A., Flores, J. M., and Rudich, Y.: The optical, physical and chemical properties of the products of glyoxal uptake on ammonium sulfate seed aerosols, Atmos. Chem. Phys., 11, 9697-9707, doi:10.5194/acp-11-96972011, 2011.

Vandaele, A., Hermans, C., Simon, P., Carleer, M., Colin, R., Fally, S., Merienne, M., Jenouvrier, A., and Coquart, B.: Measurements of the $\mathrm{NO}_{2}$ absorption cross-section from $42000 \mathrm{~cm}^{-1}$ to $10000 \mathrm{~cm}^{-1}(238-1000 \mathrm{~nm})$ at $220 \mathrm{~K}$ and $294 \mathrm{~K}$, J. Quant. Spectrosc. Ra., 59, 171-184, doi:10.1016/S0022-4073(97)00168-4, 1998.

Volkamer, R., Spietz, P., Burrows, J., and Platt, U.: Highresolution absorption cross-section of glyoxal in the UV-vis and IR spectral ranges, J. Photoch. Photobio. A, 172, 35-46, doi:10.1016/j.jphotochem.2004.11.011, 2005.

Volkamer, R., Martini, F. S., Molina, L. T., Salcedo, D., Jimenez, J. L., and Molina, M. J.: A missing sink for gas-phase glyoxal in Mexico City: Formation of secondary organic aerosol, Geophys. Res. Lett., 34, L19807, doi:10.1029/2007GL030752, 2007.

Volkamer, R., Coburn, S., Dix, B., and Sinreich, R.: MAX-DOAS observations from ground, ship, and research aircraft: maximizing signal-to-noise to measure "weak" absorbers, Proc. SPIE, 7462, 746203, doi:10.1117/12.826792, 2009a.

Volkamer, R., Ziemann, P. J., and Molina, M. J.: Secondary Organic Aerosol Formation from Acetylene $\left(\mathrm{C}_{2} \mathrm{H}_{2}\right)$ : seed effect on SOA yields due to organic photochemistry in the aerosol aqueous phase, Atmos. Chem. Phys., 9, 1907-1928, doi:10.5194/acp9-1907-2009, 2009b.

Volkamer, R., Sheehy, P., Molina, L. T., and Molina, M. J.: Oxidative capacity of the Mexico City atmosphere - Part 1: A radical source perspective, Atmos. Chem. Phys., 10, 6969-6991, doi:10.5194/acp-10-6969-2010, 2010.

Wagner, T., von Friedeburg, C., Wenig, M., Otten, C., and Platt, $\mathrm{U}$.: UV-visible observations of atmospheric $\mathrm{O}_{4}$ absorptions using direct moonlight and zenith-scattered sunlight for clearsky and cloudy sky conditions, J. Geophys. Res., 107, 4424, doi:10.1029/2001JD001026, 2002.
Wagner, T., Dix, B., von Friedeburg, C., Friess, U., Sanghavi, S., Sinreich, R., and Platt, U.: MAX-DOAS $\mathrm{O}_{4}$ measurements: A new technique to derive information on atmospheric aerosols - Principles and information content, J. Geophys. Res., 109, D22205, doi:10.1029/2004JD004904, 2004.

Wagner, T., Burrows, J. P., Deutschmann, T., Dix, B., von Friedeburg, C., Frieß, U., Hendrick, F., Heue, K.-P., Irie, H., Iwabuchi, H., Kanaya, Y., Keller, J., McLinden, C. A., Oetjen, H., Palazzi, E., Petritoli, A., Platt, U., Postylyakov, O., Pukite, J., Richter, A., van Roozendael, M., Rozanov, A., Rozanov, V., Sinreich, R., Sanghavi, S., and Wittrock, F.: Comparison of box-airmass-factors and radiances for Multiple-Axis Differential Optical Absorption Spectroscopy (MAX-DOAS) geometries calculated from different UV/visible radiative transfer models, Atmos. Chem. Phys., 7, 1809-1833, doi:10.5194/acp-7-1809-2007, 2007.

Wagner, T., Deutschmann, T., and Platt, U.: Determination of aerosol properties from MAX-DOAS observations of the Ring effect, Atmos. Meas. Tech., 2, 495-512, doi:10.5194/amt-2-4952009, 2009.

Wahner, A., Callies, J., Dorn, H. P., Platt, U., and Schiller, C.: Near Uv Atmospheric Absorption-Measurements of Column Abundances during Airborne Arctic Stratospheric Expedition, January-February 1989, 1. Technique and $\mathrm{No}_{2}$ Observations, Geophys. Res. Lett., 17, 497-500, doi:10.1029/GL017i004p00497, 1990a.

Wahner, A., Callies, J., Dorn, H. P., Platt, U., and Schiller, C.: Near Uv Atmospheric Absorption-Measurements of Column Abundances during Airborne Arctic Stratospheric Expedition, January-February 1989, 3. Bro Observations, Geophys. Res. Lett., 17, 517-520, doi:10.1029/GL017i004p00517, 1990b.

Wang, P., Richter, A., Bruns, M., Rozanov, V. V., Burrows, J. P., Heue, K.-P., Wagner, T., Pundt, I., and Platt, U.: Measurements of tropospheric $\mathrm{NO}_{2}$ with an airborne multi-axis DOAS instrument, Atmos. Chem. Phys., 5, 337-343, doi:10.5194/acp-5-337-2005, 2005.

Wang, P., Richter, A., Bruns, M., Burrows, J. P., Scheele, R., Junkermann, W., Heue, K.-P., Wagner, T., Platt, U., and Pundt, I.: Airborne multi-axis DOAS measurements of tropospheric $\mathrm{SO}_{2}$ plumes in the Po-valley, Italy, Atmos. Chem. Phys., 6, 329-338, doi:10.5194/acp-6-329-2006, 2006.

Weidner, F., Bösch, H., Bovensmann, H., Burrows, J. P., Butz, A., Camy-Peyret, C., Dorf, M., Gerilowski, K., Gurlit, W., Platt, U., von Friedeburg, C., Wagner, T., and Pfeilsticker, K.: Balloonborne limb profiling of $\mathrm{UV} / \mathrm{vis}$ skylight radiances, $\mathrm{O}_{3}, \mathrm{NO}_{2}$, and $\mathrm{BrO}$ : technical set-up and validation of the method, Atmos. Chem. Phys., 5, 1409-1422, doi:10.5194/acp-5-1409-2005, 2005.

Wittrock, F., Oetjen, H., Richter, A., Fietkau, S., Medeke, T., Rozanov, A., and Burrows, J. P.: MAX-DOAS measurements of atmospheric trace gases in Ny-Ålesund - Radiative transfer studies and their application, Atmos. Chem. Phys., 4, 955-966, doi:10.5194/acp-4-955-2004, 2004.

Zaveri, R. A., Shaw, W. J., Cziczo, D. J., Schmid, B., Ferrare, R. A., Alexander, M. L., Alexandrov, M., Alvarez, R. J., Arnott, W. P., Atkinson, D. B., Baidar, S., Banta, R. M., Barnard, J. C., Beranek, J., Berg, L. K., Brechtel, F., Brewer, W. A., Cahill, J. F., Cairns, B., Cappa, C. D., Chand, D., China, S., Comstock, J. M., Dubey, M. K., Easter, R. C., Erickson, M. H., Fast, J. 
D., Floerchinger, C., Flowers, B. A., Fortner, E., Gaffney, J. S., Gilles, M. K., Gorkowski, K., Gustafson, W. I., Gyawali, M., Hair, J., Hardesty, R. M., Harworth, J. W., Herndon, S., Hiranuma, N., Hostetler, C., Hubbe, J. M., Jayne, J. T., Jeong, H., Jobson, B. T., Kassianov, E. I., Kleinman, L. I., Kluzek, C., Knighton, B., Kolesar, K. R., Kuang, C., Kubátová, A., Langford, A. O., Laskin, A., Laulainen, N., Marchbanks, R. D., Mazzoleni, C., Mei, F., Moffet, R. C., Nelson, D., Obland, M. D., Oetjen, H., Onasch, T. B., Ortega, I., Ottaviani, M., Pekour, M., Prather, K. A., Radney, J. G., Rogers, R. R., Sandberg, S. P., Sedlacek, A., Senff, C. J., Senum, G., Setyan, A., Shilling, J. E., Shrivastava, M., Song, C., Springston, S. R., Subramanian, R., Suski, K., Tomlinson, J., Volkamer, R., Wallace, H. W., Wang, J., Weickmann, A. M., Worsnop, D. R., Yu, X.-Y., Zelenyuk, A., and Zhang, Q.: Overview of the 2010 Carbonaceous Aerosols and Radiative Effects Study (CARES), Atmos. Chem. Phys., 12, 7647-7687, doi:10.5194/acp-12-7647-2012, 2012.
Zieger, P., Weingartner, E., Henzing, J., Moerman, M., de Leeuw, G., Mikkilä, J., Ehn, M., Petäjä, T., Clémer, K., van Roozendael, M., Yilmaz, S., Frieß, U., Irie, H., Wagner, T., Shaiganfar, R., Beirle, S., Apituley, A., Wilson, K., and Baltensperger, U.: Comparison of ambient aerosol extinction coefficients obtained from in-situ, MAX-DOAS and LIDAR measurements at Cabauw, Atmos. Chem. Phys., 11, 2603-2624, doi:10.5194/acp11-2603-2011, 2011. 